\title{
DINÂMICA DA ESTRUTURA FITOSSOCIOLÓGICA DA REGENERAÇÃO NATURAL EM SUB-BOSQUE DE Mimosa scabrella Bentham EM ÁREA MINERADA, EM POÇOS DE CALDAS, MG'
}

\author{
Mauro Eloi Nappo ${ }^{2}$, James Jackson Griffith ${ }^{3}$, Sebastião Venâncio Martins ${ }^{3}$, Paulo De Marco Júnior ${ }^{4}$, \\ Agostinho Lopes de Souza ${ }^{3}$ e Ary Teixeira de Oliveira Filho
}

\begin{abstract}
RESUMO - Como estratégia de reabilitação de área minerada foram realizados, no ano agrícola 1982/1983, hidrossemeadura de gramíneas e leguminosa e o plantio puro de Mimosa scabrella Bentham em Poços de Caldas, MG. Em 1997 foi implantado um conjunto de 19 parcelas permanentes de $50 \mathrm{~m}^{2}$ nessa área, para caracterização inicial do processo de regeneração natural. Em 2000, foi realizado o segundo inventário nas parcelas, para caracterização do processo de dinâmica da regeneração natural, que é o objeto deste trabalho. O processo de dinâmica da regeneração natural foi caracterizado mediante análises quantitativas e qualitativas da composição florística e da estrutura horizontal e vertical. O povoamento florestal do Retiro-Branco está sobre intensa atividade de estruturação, caracterizando o estágio inicial do processo de sucessão. O declínio do povoamento puro de Mimosa escabrella está modificando a ordem anteriormente estabelecida para o processo de sucessão da área, provocando a diversificação de condições de sítio e, assim, selecionando a ocupação deste em função dos grupos ecológicos, sendo as espécies pioneiras as mais favorecidas. As espécies secundárias são as de maior dominância nas maiores classes de altura e de diâmetro, sendo as principais responsáveis pela edificação do estrato superior, em especial a espécie Miconia sellowiana. As espécies que apresentaram melhor desempenho na colonização e estruturação da regeneração natural do Retiro-Branco, nos dois inventários, foram Miconia sellowiana, Psychotria sessilis, Leandra melastomoides, Clethra scabra, Myrsine umbellata, Miconia pepericarpa, Tibouchina candolleana, Cordia superba, Cestrum amictum, Alchornea triplinervia, Casearia sylvestris, Blepharocalyx salicifolius, Myrcia rostrata e Schinus terebinthifolius, sendo indicadas como espécies para uso nos programas de reabilitação de áreas mineradas em condições semelhantes sobre a estratégia sucessional.
\end{abstract}

Palavras-chave: revegetação de áreas degradadas, fitossociologia , regeneração natural e Mimosa scabrella

\section{PHYTOSOCIOLOGY STRUCTURE DYNAMICS OF NATURAL REGENERATION IN UNDERSTORY OF Mimosa scabrella Bentham IN MINED AREA, POCOS DE CALDAS, BRAZIL}

\begin{abstract}
As part of mine rehabilitation strategy, herbaceous species hydroseeding and Mimosa scabrella Bentham seedling planting was carried out in 1982/1983 the Retiro-Branco bauxite mine site. In 1997, 19 sample plots of $50 \mathrm{~m}^{2}$ were established for initial characterization of the natural regeneration process. In 2000, a second inventory was performed in those same sample plots, to characterize natural regeneration dynamics. This process was characterized by means of quantitative and qualitative analyses of floristic composition and horizontal and vertical structures. The forest succession at Retiro-Branco was found to be undergoing intense restructuring activity, characterizing initial stage of succession. The decline of Mimosa scabrella pure stands is modifying the successional order that previously occurred in this area, causing diversity in site conditions. Occupation of these sites occurs by ecological groups, pioneer species being favored in the process. Secondary
\end{abstract}

\footnotetext{
${ }^{1}$ Recebido em 07.05.2003 e aceito para publicação em 10.08.2004.

${ }^{2}$ Departamento de Fitotecnia - UFES, CEP 29.500-000 Alegre (ES).

${ }^{3}$ Departamento de Engenharia Florestal - UFV, CEP 36570-000 Viçosa (MG),

${ }^{4}$ Departamento de Biologia Geral - UFV, CEP 36570-000 Viçosa (MG).

${ }^{5}$ Departamento de Ciências Florestais - UFLA, CEP 37.200-000 Lavras (MG).
} 
species, especially Miconia sellowiana, dominate the classes with greatest height and diameter, and are the most responsible for construction of the superior stratum. Species which presented the best performance in colonization and structuring of natural regeneration at Retiro-Branco for both inventories were Miconia sellowiana, Psychotria sessilis, Leandra melastomoides, Clethra scabra, Myrsine umbellata, Miconia pepericarpa, Tibouchina candolleana, Cordia superba, Cestrum amictum, Alchornea triplinervia, Casearia sylvestris, Blepharocalyx salicifolius, Myrcia rostrata and Schinus terebinthifolius. These are indicated as promising species for rehabilitation programs of mined areas with similar conditions of sucessional strategy.

Key words: Revegetation of degraded areas, phytosociology, natural regeneration and Mimosa scabrella Bentham.

\section{INTRODUÇÃO}

A realização de estudos básicos sobre a composição florística e as relações fitossociológicas entre as espécies colonizadoras de áreas fortemente perturbadas ao longo do tempo são ferramentas importantes a serem utilizadas para nortear estratégias de reabilitação e recuperação destas (NAPPO et al., 2000a), bem como possibilitar avaliações qualiquantitativas das áreas sob processo de recuperação.

No planalto de Poços de Caldas, em áreas mineradas para a extração de bauxita pela ALCOAAlumínio S.A., foram implantados povoamentos homogêneos de Mimosa scabrella Bentham como componente arbóreo do processo de revegetação, visando à reabilitação desses. Em uma dessas áreas, denominada Retiro-Branco, esse procedimento de revegetação foi realizado no ano agrícola 1981/1982. Nessa área foi implementado, no ano de 1997, um conjunto de parcelas permanentes para caracterização inicial do processo de regeneração natural, tendo como resultado os trabalhos apresentados por Nappo et al. (1999, 2000a b). Em 2000 foi realizado o segundo inventário da regeneração natural nas parcelas permanentes para caracterização do processo de dinâmica da sucessão no povoamento já citado, sendo o objeto de estudo deste trabalho.

O presente estudo tem por objetivo geral caracterizar o processo de dinâmica da regeneração natural das espécies arbóreas e arbustivas no sub-bosque do povoamento de Mimosa scabrella Bentham naquela área. Os objetivos específicos deste estudo foram: avaliar o comportamento da regeneração natural de Mimosa scabrella quanto ao potencial de formação de povoamentos homogêneos; avaliar a dinâmica das espécies Miconia sellowiana, Psychotria sessilis, Leandra melastomoides, Clethra scabra, Myrsine umbellata, Miconia pepericarpa, Tibouchina candolleana, Cordia superba, Cestrum amictum, Alchornea triplinervia, Casearia sylvestris, Blepharocalyx salicifolius, Myrcia rostrata e Schinus terebinthifolius, indicadas no primeiro inventário por Nappo et al. (2000a) como espécies de interesse para utilização na implantação de povoamentos mistos e em plantios de enriquecimento para recuperação de áreas degradadas, bem como subsidiar programas de indicação de espécies potenciais e monitoramento do desenvolvimento dos povoamentos.

\section{MATERIAL E MÉTODOS}

\subsection{A área de estudos}

O local de estudo, denominado "Retiro-Branco", de propriedade da Companhia Geral de Minas, está localizado em Poços de Caldas, MG, tem área de 6,44 ha e está a $1.500 \mathrm{~m}$ de altitude na porção superior da vertente voltada para face NE. Limita-se a montante no divisor de águas com área de pastagem plantada e a jusante com outra área sob reabilitação posterior com plantio misto de Mimosa scabrella (bracatinga), espécies arbóreas diversas e forrageiras plantadas no ano agrícola 1995/1996.

O Retiro-Branco foi submetido à atividade de mineração para a extração de bauxita entre 1978 e 1981 . Nesse período, o local foi desflorestado, teve a camada superficial de solo (de 30 a $40 \mathrm{~cm}$ ) removida, e a mineração ocorreu a uma profundidade média de 4,5 m. As atividades de reabilitação do Retiro-Branco iniciaram-se no ano agrícola 1981/1982, tendo sido feita a reconstrução topográfica do terreno tendendo à topografia original, com adoção de práticas de conservação de solos (curvas de nível e patamares) e recolocação de uma camada de aproximadamente $30 \mathrm{~cm}$ de solo superficial (armazenado no início das atividades de mineração). 
A revegetação foi feita para compor dois estratos distintos, sendo no herbáceo realizada hidrossemeadura em área total com Lolium multiflorum Lam. (azevém), Glycine wightii Willd. (soja-perene) e Melinis minutiflora Beauv. (capim-gordura), e no arbóreo o plantio homogêneo de Mimosa scabrella Bentham (bracatinga) em espaçamento $5 \mathrm{~m} \times 5 \mathrm{~m}$ (400 indivíduos/ ha), tendo, desde então, sido isolado de qualquer tipo de uso e exploração, sendo a área utilizada apenas para implementação de pesquisa científica de manejo e conservação.

\subsection{Procedimentos de campo}

Na análise da dinâmica da regeneração natural, foram identificados e medidos os indivíduos de espécies arbóreas e arbustivas com altura igual ou superior a $0,30 \mathrm{~m}$. Para isso, realizou-se um inventário florestal contínuo, com 19 parcelas permanentes de $50 \mathrm{~m}^{2}$ (5 $\mathrm{m} \times 10 \mathrm{~m}$ ), sendo a primeira amostragem em 1997 e a segunda, em 2000. Foram tomadas as medidas de Diâmetro à Altura do Solo (DAS) e de Altura Total (H).

\subsection{Dinâmica da regeneração natural}

A dinâmica da regeneração natural foi analisada mediante a comparação dos parâmetros de cada um dos inventários. Os parâmetros analisados foram: Composição Florística; Diversidade de Espécies; Equabilidade; Densidade; Freqüência; Dominância; Regeneração Natural; Estrutura Diamétrica; Espécies Raras; Taxa de Regeneração Natural; Ingresso; Mortalidade e Taxa de Crescimento. Foi avaliado, qualitativa e quantitativamente, o comportamento das espécies quanto à regeneração natural entre os dois inventários.

A diversidade florística nos inventários entre 1997 e 2000 foi estimada pelo Índice de Shannon, conforme Poole (1974). Esses inventários foram comparados entre si, mediante o teste $t$ descrito por Magurran (1988) e utilizado por Vidal et al. (1998) e Werneck et al. (2000), a seguir:

$$
H^{\prime}=\frac{N \times \ln (N)-\sum_{i=1}^{S} n_{i} \times \ln \left(n_{i}\right)}{N}
$$

$$
\begin{aligned}
& \operatorname{Var} H^{\prime}{ }_{p}=\frac{\sum_{i=1}^{S}\left(\ln \frac{n i}{N}\right)^{2}-\left(\sum_{i=1}^{S} \ln \frac{n i}{N}\right)^{2}}{N}-\frac{S-1}{2 N^{2}} ; \\
& G L=\frac{\left(\operatorname{VarH}_{1}{ }_{1}+\operatorname{Var} H_{2}^{\prime}\right)^{2}}{\left(\frac{\left(\operatorname{Var} H_{1}^{\prime}\right)^{2}}{N_{1}}\right)+\left(\frac{\left(\operatorname{Var} H_{2}^{\prime}\right)^{2}}{N_{2}}\right)} ; \\
& t=\frac{H_{1}^{{ }_{1}}-H_{2}^{{ }_{2}}}{\sqrt{\operatorname{Var} H^{\prime}+\operatorname{Var}_{1}{ }^{\prime}}} .
\end{aligned}
$$

em que: $\mathrm{H}^{\prime}$ = índice de Shannon; $\mathrm{N}$ = número de indivíduos amostrados; $\mathrm{n}_{\mathrm{i}}=$ número de indivíduos amostrados da i-ésima espécie; $\mathrm{S}=$ número de espécies amostradas; $\ln =$ logaritmo na base neperiana; e Var $\mathrm{H}_{\mathrm{i}}^{\prime}$ = variância do índice de Shannon no inventário i.

A estrutura horizontal foi quantificada mediante os parâmetros densidade, freqüência e dominância, em suas formas absolutas e relativas. Esses parâmetros dizem respeito à distribuição espacial das espécies arbóreo-arbustivas que compõem a comunidade, permitindo quantificar a participação de cada uma em relação às outras (REZENDE, 1995; CURTIS e McINTOSH, 1951; LAMPRECHT, 1964). A soma dos valores relativos da densidade (número de indivíduos), a frequiência (distribuição dos indivíduos) e a dominância (área basal) por espécie permitem obter o Índice de Valor de Importância (IVI) de cada espécie (CURTIS e McINTOSH, 1951), permitindo avaliar, de forma mais ampla, a participação das espécies da estrutura da comunidade.

Foram consideradas espécies raras aquelas que apresentaram um único indivíduo na amostragem, sendo quantificadas em porcentagem do número total de espécies, conforme Martins (1993).

A determinação do parâmetro regeneração natural permite que sejam feitas inferências sobre a origem da floresta e previsões sobre seu desenvolvimento e aproveitamento sob diferentes formas de tratamento (HOSOKAWA, 1986; CARVALHO, 1987). Neste estudo, foi utilizada a metodologia apresentada por Volpato (1994) para se obter o índice de regeneração natural por classe de tamanho de planta $\left(\mathrm{RNC}_{\mathrm{ij}}\right)$, permitindo

R. Árvore, Viçosa-MG, v.28, n.6, p.811-829, 2004 
adquirir informações mais detalhadas do comportamento das espécies em regeneração, evitando que as classes de menor tamanho de plantas possuam maior peso na estrutura da comunidade, em razão de apresentarem maior densidade, podendo, dessa forma, mascarar aspectos importantes quanto à dinâmica da sucessão vegetal e à contribuição de cada espécie nas fases do processo. As expressões utilizadas foram:

$$
\begin{aligned}
& R N C_{i j}=\frac{D R_{i j}+F R_{i j}}{2} \\
& R N T_{i}=\sum_{j=1}^{Z} R N C_{i j}
\end{aligned}
$$

em que: $\mathrm{RNC}_{\mathrm{ij}}=$ regeneração natural da i-ésima espécie na j-ésima classe de tamanho; $\mathrm{RNT}_{\mathrm{i}}=$ regeneração natural total da i-ésima espécie; $\mathrm{DRr}_{\mathrm{ij}}=$ densidade relativa para a i-ésima espécie na j-ésima classe de tamanho; $\mathrm{FR}_{\mathrm{ij}}=$ freqüência relativa da i-ésima espécie na jésima classe de tamanho; e $\mathrm{Z}=$ número de classes de tamanho de planta.

O ingresso é o processo pelo qual as árvores entram na nova etapa de medição, e a mortalidade é o número de plantas que morreram durante esse espaço de tempo. Essas informações são de extrema importância para que as florestas naturais possam ser utilizadas em base sustentada (AZEVEDO et al., 1995). A partir das estimativas do número ou da área basal dos indivíduos que ingressaram ou morreram são estimadas as taxas de ingresso e mortalidade, conforme Ferreira (1997):

$$
T I_{i}=\left(\frac{n_{i}}{N_{i}}\right) \cdot 100
$$

em que: $\mathrm{TI}_{\mathrm{i}}=$ taxa de ingresso na i-ésima classe de altura; $\mathrm{n}_{\mathrm{i}}=$ número de indivíduos ou área basal dos indivíduos que ingressaram na i-ésima classe de altura, no final do período de monitoramento; e $\mathrm{N}_{\mathrm{i}}=$ número de indivíduos ou área basal dos indivíduos vivos na iésima classe de altura, no final do período de monitoramento.

$$
T M_{i}=\left(\frac{n_{i}}{N_{i}}\right) \cdot 100
$$

em que: $\mathrm{TM}_{\mathrm{i}}=$ taxa de mortalidade na i-ésima classe de altura; $\mathrm{n}_{\mathrm{i}}=$ número de indivíduos ou área basal dos indivíduos mortos, na i-ésima classe de altura, no final do período de monitoramento; e $\mathrm{N}_{\mathrm{i}}=$ número de indivíduos ou área basal, dos indivíduos mortos, na i-ésima classe de altura, no início do período de monitoramento.
As estimativas de incremento periódico anual (IPA), em diâmetro ou em área basal, por espécie, por classe de altura e por grupo ecofisiológico, no período de monitoramento, foram calculadas conforme Ferreira (1997):

$$
I P A_{i j}=\sum_{k=1}^{N}\left(D_{k, j+1}-D_{k, j}\right) \cdot\left(\frac{10}{N \cdot P}\right)
$$

em que: IPA = incremento periódico anual, em diâmetro $(\mathrm{mm} /$ ano) ou em área basal ( $\left.\mathrm{m}^{2} / \mathrm{ano}\right) ; \mathrm{D}=$ diâmetro de tronco à altura do solo; $\mathrm{k}=$ espécie; $\mathrm{j}=$ ocasiões de medição; $\mathrm{N}$ = número de indivíduos amostrados ou área basal, por espécie e por classe de diâmetro; e $\mathrm{P}$ = intervalo de monitoramento em anos.

A combinação entre esses três componentes com o número ou a área basal de indivíduos remanescentes no final do período de monitoramento fornece os componentes normalmente utilizados na estimativa do crescimento florestal, considerando-se a inclusão e a exclusão do ingresso (HUSCH et al., 1993). O crescimento pode ser obtido segundo as seguintes expressões:

$$
\mathrm{Cb}=\mathrm{Gf}-\mathrm{Gi}
$$

em que: $\mathrm{Cb}=$ crescimento bruto, excluindo o ingresso; Gf = número de indivíduos (N/ha) ou área basal $\left(\mathrm{m}^{2} / \mathrm{ha}\right)$, dos indivíduos vivos nos dois inventários; e Gi = número de indivíduos (N/ha) ou área basal $\left(\mathrm{m}^{2} / \mathrm{ha}\right)$ inicial dos indivíduos vivos nos dois inventários, no início do período.

\section{RESULTADOS E DISCUSSÃO}

\subsection{Dinâmica da composição florística}

No primeiro inventário, em 1997, foram medidos e identificados, no conjunto de parcelas, 1.946 indivíduos com altura igual ou superior a $0,3 \mathrm{~m}$, pertencentes a 26 famílias, 47 gêneros e 63 espécies, sendo 23 pioneiras, 21 secundárias e 19 clímax. No segundo inventário, em 2000, foram medidos e identificados, no mesmo conjunto de parcelas, 2.889 indivíduos com altura igual ou superior a $0,3 \mathrm{~m}$, pertencentes a 30 famílias, 58 gêneros e 77 espécies, sendo 28 pioneiras, 29 secundárias e 20 clímax. Em ambos os inventários, as famílias com maior número de espécies foram: Compositae, com 10, Myrtaceae com 9 e Melastomataceae com 7. 
Todas as espécies que ocorreram no primeiro inventário também ocorreram no segundo, e este, por sua vez, apresentou, em relação ao primeiro, um acréscimo de: $4(15,38 \%)$ famílias novas, Anacardiaceae, Bignoniaceae, Malpighiaceae e Piperaceae; 14 (22,22\%) espécies, Astronium graviolens, Shinus terebinthifolious, Tabebuia alba, Cordia ecalyculata,
Prokia crucis, Byrsonima lancifolia, Trichilia silvatica, Myrsine gardineriana, Piper sp., Alibertia sessilis, Rubiaceae 1, Aureliana velutina, Solanum swartzianum e Solanum robustum; e 943 (48,46\%) indivíduos. No Quadro 1 é apresentada a lista de espécies, com os respectivos famílias botânicas, grupo ecológico, síndrome de dispersão de sementes e hábito, por inventário.

Quadro 1 - Lista de espécies encontradas nos inventários da regeneração natural na área do Retiro-Branco, em Poços de Caldas, Minas Gerais

Table 1 - List of species recorded as natural regeneration in understory of Mimosa scabrella Benth. pure stands, at RetiroBranco, Poços de Caldas, Brazil

\begin{tabular}{|c|c|c|c|c|c|}
\hline \multirow[t]{2}{*}{ Famílias e Respectivas Espécies } & \multicolumn{2}{|c|}{ Inventário } & \multirow{2}{*}{$\begin{array}{l}\text { Tipo de } \\
\text { Dispersão }\end{array}$} & \multirow{2}{*}{$\begin{array}{c}\text { Grupo } \\
\text { Ecológico }\end{array}$} & \multirow[t]{2}{*}{ Hábito } \\
\hline & 1997 & 2000 & & & \\
\hline \multicolumn{6}{|l|}{ ANACARDIACEAE } \\
\hline Astronium graveolens Jacq. & & $\mathrm{X}$ & Anemocórica & SI & Arbóreo \\
\hline Schinus terebinthifolius Raddi & & $\mathrm{X}$ & Zoocórica & $\mathrm{P}$ & Arbustivo \\
\hline \multicolumn{6}{|l|}{ ARALIACEAE } \\
\hline Schefflera angustissima (E. March) D.Frodin & $\mathrm{X}$ & $\mathrm{X}$ & Zoocórica & $\mathrm{P}$ & Arbóreo \\
\hline \multicolumn{6}{|l|}{ BIGNONIACEAE } \\
\hline $\begin{array}{l}\text { Tabebuia alba (Cham.) Sandw. } \\
\text { BORAGINACEAE }\end{array}$ & \multicolumn{3}{|c|}{ BORAGINACEAE } & SI & Arbóreo \\
\hline Cordia ecalyculata Vell. & & $\mathrm{X}$ & Zoocórica & SI & Arbóreo \\
\hline Cordia superba Cham. & $\mathrm{X}$ & $\mathrm{X}$ & Zoocórica & ST & Arbóreo \\
\hline \multicolumn{6}{|l|}{ CELASTRACEAE } \\
\hline Maytenus salicifolia Reisseck & $\mathrm{X}$ & $\mathrm{X}$ & Zoocórica & ST & Arbóreo \\
\hline \multicolumn{6}{|l|}{ CLETRHACEAE } \\
\hline Clethra scabra Loisel & $\mathrm{X}$ & $\mathrm{X}$ & Anemocórica & $\mathrm{P}$ & Arbóreo \\
\hline \multicolumn{6}{|l|}{ COMPOSITAE } \\
\hline Alomia fastigiata (Gardner) Benth. & $\mathrm{X}$ & $\mathrm{X}$ & Anemocórica & $\mathrm{P}$ & Arbustivo \\
\hline Baccharis dracunculifolia DC. & $\mathrm{X}$ & $\mathrm{X}$ & Anemocórica & $\mathrm{P}$ & Arbustivo \\
\hline Baccharis punctulata DC. & $\mathrm{X}$ & $\mathrm{X}$ & Anemocórica & $\mathrm{P}$ & Arbustivo \\
\hline Baccharis semiserrata (Steud). G.M.Barroso & $\mathrm{X}$ & $\mathrm{X}$ & Anemocórica & $\mathrm{P}$ & Arbóreo \\
\hline Baccharis serrulata (Lam.) Pers. & $\mathrm{X}$ & $\mathrm{X}$ & Anemocórica & $\mathrm{P}$ & Arbustivo \\
\hline Eupatorium inulaefolium Hier. & $\mathrm{X}$ & $\mathrm{X}$ & Anemocórica & $\mathrm{P}$ & Arbustivo \\
\hline Eupatorium velutinun Gardner & $\mathrm{X}$ & $\mathrm{X}$ & Anemocórica & $\mathrm{P}$ & Arbustivo \\
\hline Vernonia ferruginea Less H. Robison & $\mathrm{X}$ & $\mathrm{X}$ & Anemocórica & $\mathrm{P}$ & Arbustivo \\
\hline Vernonia polyanthes Less & $\mathrm{X}$ & $\mathrm{X}$ & Anemocórica & $\mathrm{P}$ & Arbóreo \\
\hline Vernonia westiniana Less & $\mathrm{X}$ & $\mathrm{X}$ & Anemocórica & $\mathrm{P}$ & Arbustivo \\
\hline \multicolumn{6}{|l|}{ CUNONIACEAE } \\
\hline Lamanonia ternata Vell. & $\mathrm{X}$ & $\mathrm{X}$ & Anemocórica & SI & Arbóreo \\
\hline \multicolumn{6}{|l|}{ ERYTHROXYLACEAE } \\
\hline Erythroxylum deciduun A.St.-Hil. & $\mathrm{X}$ & $\mathrm{X}$ & Zoocórica & ST & Arbóreo \\
\hline \multicolumn{6}{|l|}{ EUPHORBIACEAE } \\
\hline Alchornea triplinervea (Spreng.) Muel. Arg. & $\mathrm{X}$ & $\mathrm{X}$ & Zoocórica & SI & Arbóreo \\
\hline Pera glabata (Schatl.) Poepp. & $X$ & $\mathrm{X}$ & Zoocórica & ST & Arbóreo \\
\hline Sapium glandulosum (L.) Moroug. & $\mathrm{X}$ & $\mathrm{X}$ & Zoocórica & $\mathrm{P}$ & Arbóreo \\
\hline \multicolumn{6}{|l|}{ FLACOURTIACEAE } \\
\hline Casearia decandra Jacquin & $\mathrm{X}$ & $\mathrm{X}$ & Zoocórica & CL & Arbóreo \\
\hline
\end{tabular}


Quadro 1 - cont.

Table 1 - cont.

\begin{tabular}{|c|c|c|c|c|c|}
\hline \multirow[t]{2}{*}{ Famílias e Respectivas Espécies } & \multicolumn{2}{|c|}{ Inventário } & \multirow{2}{*}{$\begin{array}{c}\text { Tipo de } \\
\text { Dispersão }\end{array}$} & \multirow{2}{*}{$\begin{array}{c}\text { Grupo } \\
\text { Ecológico }\end{array}$} & \multirow[t]{2}{*}{ Hábito } \\
\hline & 1997 & 2000 & & & \\
\hline \multicolumn{6}{|l|}{ FLACOURTIACEAE } \\
\hline Casearia sylvestris $\mathrm{Sw}$. & $\mathrm{X}$ & $\mathrm{X}$ & Zoocórica & $\mathrm{P}$ & Arbóreo \\
\hline Prockia crucis P.Browne & & $\mathrm{X}$ & Zoocórica & SI & Arbóreo \\
\hline Xylosma pseudosalzmannii Sleumer & $\mathrm{X}$ & $\mathrm{X}$ & Zoocórica & SI & Arbóreo \\
\hline \multicolumn{6}{|l|}{ LAURACEAE } \\
\hline Aniba firmula (Nees \& Mart) Mez & $\mathrm{X}$ & $\mathrm{X}$ & Zoocórica & ST & Arbóreo \\
\hline Cryptocarya aschersoniana $\mathrm{Mez}$ & $\mathrm{X}$ & $\mathrm{X}$ & Zoocórica & CS & Arbóreo \\
\hline Ocotea pulchella (Nees) Mez & $\mathrm{X}$ & $\mathrm{X}$ & Zoocórica & CL & Arbóreo \\
\hline \multicolumn{6}{|l|}{ LEGUMINOSAE MIMOSOIDEAE } \\
\hline Mimosa scabrella Benth. & $\mathrm{X}$ & $\mathrm{X}$ & Autocórica & $\mathrm{P}$ & Arbóreo \\
\hline \multicolumn{6}{|l|}{ LEGUMINOSAE CAESALPINIOIDEAE } \\
\hline Senna bicapsularis (L.) Irwin \& Barneby & $\mathrm{X}$ & $\mathrm{X}$ & Zoocórica & $\mathrm{P}$ & Arbustivo \\
\hline \multicolumn{6}{|l|}{ LEGUMINOSAE PAPILIONOIDEAE } \\
\hline Machaerium nyctitans (Vell.) Benth. & $\mathrm{X}$ & $\mathrm{X}$ & Anemocórica & CL & Arbóreo \\
\hline Machaerium stipitatum (DC.) Vog. & $\mathrm{X}$ & $\mathrm{X}$ & Anemocórica & CL & Arbóreo \\
\hline \multicolumn{6}{|l|}{ MALPIGHIACEAE } \\
\hline Byrsonima lancifolia A. Juss. & & $\mathrm{X}$ & Zoocórica & ST & Arbóreo \\
\hline \multicolumn{6}{|l|}{ MELASTOMATACEAE } \\
\hline Leandra lacunosa Cogn. & $\mathrm{X}$ & $\mathrm{X}$ & Zoocórica & ST & Arbustivo \\
\hline Leandra melastomoides Raddi & $\mathrm{X}$ & $\mathrm{X}$ & Zoocórica & ST & Arbustivo \\
\hline Miconia albicans (SW.) Triana & $\mathrm{X}$ & $\mathrm{X}$ & Zoocórica & $\mathrm{P}$ & Arbustivo \\
\hline Miconia pepericarpa DC. & $\mathrm{X}$ & $\mathrm{X}$ & Zoocórica & CL & Arbustivo \\
\hline Miconia sellowiana Naud. & $\mathrm{X}$ & $\mathrm{X}$ & Zoocórica & SI & Arbóreo \\
\hline Tibouchina candolleana (DC) Cogn. & $\mathrm{X}$ & $\mathrm{X}$ & Anemocórica & $\mathrm{P}$ & Arbórea \\
\hline Trembleya parviflora (D. Don) Cogn. & $\mathrm{X}$ & $\mathrm{X}$ & Anemocórica & $\mathrm{P}$ & Arbustivo \\
\hline \multicolumn{6}{|l|}{ MELIACEAE } \\
\hline Cabralea canjerana (Vell.) Mart & $\mathrm{X}$ & $\mathrm{X}$ & Zoocórica & ST & Arbóreo \\
\hline Cedrella fissilis Vell. & $\mathrm{X}$ & $\mathrm{X}$ & Anemocórica & SI & Arbóreo \\
\hline Trichilia silvatica C. DC. & & $\mathrm{X}$ & Zoocórica & SI & Arbóreo \\
\hline \multicolumn{6}{|l|}{ MYRSINACEAE } \\
\hline Cybianthus cuneifolius Mart. & $\mathrm{X}$ & $\mathrm{X}$ & Zoocórica & CS & Arbóreo \\
\hline Myrsine lancifolia Mart. & $\mathrm{X}$ & $\mathrm{X}$ & Zoocórica & CL & Arbóreo \\
\hline Myrsine gardneriana A.DC. & & $\mathrm{X}$ & Zoocórica & CL & Arbóreo \\
\hline Myrsine umbellata Mart. & $\mathrm{X}$ & $\mathrm{X}$ & Zoocórica & CL & Arbóreo \\
\hline \multicolumn{6}{|l|}{ MYRTACEAE } \\
\hline Blepharocalyx salicifolius (Kunth) Berg. & $\mathrm{X}$ & $\mathrm{X}$ & Zoocórica & $\mathrm{P}$ & Arbóreo \\
\hline Gomidesia anacardifolia Berg. & $\mathrm{X}$ & $\mathrm{X}$ & Zoocórica & ST & Arbóreo \\
\hline Myrcia formosiana DC. & $\mathrm{X}$ & $\mathrm{X}$ & Zoocórica & ST & Arbóreo \\
\hline Myrcia rostrata DC. & $\mathrm{X}$ & $\mathrm{X}$ & Zoocórica & $\mathrm{P}$ & Arbóreo \\
\hline Myrcia tomentosa DC. & $\mathrm{X}$ & $\mathrm{X}$ & Zoocórica & CL & Arbóreo \\
\hline Myrciaria tenella (DC.) & $\mathrm{X}$ & $\mathrm{X}$ & Zoocórica & SI & Arbustivo \\
\hline Pimenta pseudocaryophyllus (Gomes) Landrum & $\mathrm{X}$ & $\mathrm{X}$ & Zoocórica & ST & Arbóreo \\
\hline Psidium cinereum Mart. ex DC. & $\mathrm{X}$ & $\mathrm{X}$ & Zoocórica & CL & Arbustivo \\
\hline Siphoneugena densiflora Berg. & $\mathrm{X}$ & $\mathrm{X}$ & Zoocórica & CL & Arbóreo \\
\hline \multicolumn{6}{|l|}{ PIPERACEAE } \\
\hline Piper sp. & & $\mathrm{X}$ & Zoocórica & $\mathrm{P}$ & Arbustivo \\
\hline \multicolumn{6}{|l|}{ PROTEACEAE } \\
\hline $\begin{array}{l}\text { Roupala brasiliensis Klotsch } \\
\text { RHAMNACEAE }\end{array}$ & $\mathrm{X}$ & $\mathrm{X}$ & Anemocórica & $\mathrm{ST}$ & Arbóreo \\
\hline - Hovenia dulcis Thumb. - & $\underline{X}$ & $\underline{X}$. & Zoocórica & $-\frac{C L}{-}$ & A Arbóreo \\
\hline
\end{tabular}

R. Árvore, Viçosa-MG, v.28, n.6, p.811-829, 2004 
Quadro 1 - cont.

Table 1 - cont.

\begin{tabular}{|c|c|c|c|c|c|}
\hline \multirow[t]{2}{*}{ Famílias e Respectivas Espécies } & \multicolumn{2}{|c|}{ Inventário } & \multirow{2}{*}{$\begin{array}{c}\text { Tipo de } \\
\text { Dispersão }\end{array}$} & \multirow{2}{*}{$\begin{array}{c}\text { Grupo } \\
\text { Ecológico }\end{array}$} & \multirow[t]{2}{*}{ Hábito } \\
\hline & 1997 & 2000 & & & \\
\hline \multicolumn{6}{|l|}{ ROSACEAE } \\
\hline Prunus myrtifolia (L.) Urban & $\mathrm{X}$ & $\mathrm{X}$ & Zoocórica & SI & Arbóreo \\
\hline Rubus brasiliensis Mart. & $\mathrm{X}$ & $\mathrm{X}$ & Zoocórica & SI & Arbustivo \\
\hline \multicolumn{6}{|l|}{ RUBIACEAE } \\
\hline Alibertia sessilis (Vell.) K.Schum. & & $\mathrm{X}$ & Zoocórica & ST & Arbóreo \\
\hline Alibertia concolor (Cham) K.Schum. & $\mathrm{X}$ & $\mathrm{X}$ & Zoocórica & ST & Arbóreo \\
\hline Psychotria sessilis (Vell) Muel. Arg. & $\mathrm{X}$ & $\mathrm{X}$ & Zoocórica & $\mathrm{CL}$ & Arbóreo \\
\hline Rubiaceae 1 & & $\mathrm{X}$ & Zoocórica & ST & Arbóreo \\
\hline \multicolumn{6}{|l|}{ RUTACEAE } \\
\hline Zanthoxylum rhoifolium Lam. & $\mathrm{X}$ & $\mathrm{X}$ & Zoocórica & $\mathrm{CL}$ & Arbóreo \\
\hline \multicolumn{6}{|l|}{ SAPINDACEAE } \\
\hline Cupania vernalis Camb. & $\mathrm{X}$ & $\mathrm{X}$ & Zoocórica & $\mathrm{CL}$ & Arbóreo \\
\hline Matayba juglandifolia (Camb.) Radlk. & $\mathrm{X}$ & $\mathrm{X}$ & Zoocórica & CS & Arbóreo \\
\hline \multicolumn{6}{|l|}{ SOLANACEAE } \\
\hline Aureliana velutina Sendt. & & $\mathrm{X}$ & Zoocórica & $\mathrm{P}$ & Arbustivo \\
\hline Cestrum amictum Schlecht. & $\mathrm{X}$ & $\mathrm{X}$ & Zoocórica & $\mathrm{P}$ & Arbustivo \\
\hline Solanum granuloso-leprosum Dun. & $\mathrm{X}$ & $\mathrm{X}$ & Zoocórica & $\mathrm{P}$ & Arbóreo \\
\hline Solanum swartzianum Roem. \& Schult. & & $\mathrm{X}$ & Zoocórica & $P$ & Arbustivo \\
\hline Solanum robustum Windl. & & $\mathrm{X}$ & Zoocórica & $\mathrm{P}$ & Arbustivo \\
\hline \multicolumn{6}{|l|}{ THYMELIACEAE } \\
\hline Daphnopsis fasciculata (Meisner) Nevl. & $\mathrm{X}$ & $\mathrm{X}$ & Zoocórica & $\mathrm{CL}$ & Arbóreo \\
\hline \multicolumn{6}{|l|}{ VOCHYSIACEAE } \\
\hline Vochysia tucanorum Mart & $\mathrm{X}$ & $\mathrm{X}$ & Anemocórica & $\mathrm{P}$ & Arbóreo \\
\hline
\end{tabular}

Em 1997, o porcentual de espécies raras foi de $25,0 \%$, passando em 2000 para 25,9\%, mantendo-se próximo dos valores encontrados em florestas tropicais (MARTINS, 1993).

A dinâmica dos componentes da diversidade florística (riqueza e equabilidade) e a do número de indivíduos por estrato, nos dois inventários, são apresentadas nos Quadros 2 e 3, respectivamente.

Na classe 1 de altura da regeneração natural ( $\mathrm{H}$ entre 0,3 e 1,5 m) foi observado um grande aumento da densidade de indivíduos (NI) da ordem de $45,16 \%$ e do número de espécies (NE) da ordem de 27,27\%, de 1997 para 2000. A proporção NI/NE em 1997 (25,53/1) e em 2000 (29,11/ 1) aumentou $14,02 \%$, ocasionando a diminuição da diversidade, expressa tanto pelo índice de Shannon (H') quanto pela diminuição da eqüabilidade, expressa pelo índice de Pielou (J).

$\mathrm{Na}$ classe 2 de altura da regeneração natural $(\mathrm{H}$ entre 1,51 e $3,0 \mathrm{~m}$ ) correu aumento da densidade no número de indivíduos da ordem de $21,08 \%$ e no número de espécies (NE) da ordem de 28,13\%, de 1997 para
2000. A proporção NI/NE em 1997 (12,16/1) e em 2000 $(11,48 / 1)$ apresentou diminuição de 5,59\%, refletindo na elevação da diversidade, expressa pelo índice de Shannon (H'), e no aumento da eqüabilidade, expressa pelo índice de Pielou (J).

$\mathrm{Na}$ classe 3 de altura da regeneração natural $(\mathrm{H}>3,0 \mathrm{~m})$ ocorreu o aumento da densidade do número de indivíduos da ordem de $148,37 \%$ e do número de espécies (NE) da ordem de 75,00\%, de 1997 para 2000. A proporção NI/NE em 1997 (9,56/1) e em 2000 $(13,57 / 1)$ apresentou aumento de $41,95 \%$, refletindo no aumento da diversidade, expresso pelo índice de Shannon (H'); no entanto, houve queda da equabilidade, expressa pelo índice de Pielou (J).

Na regeneração natural como um todo, não se considerando a divisão em estratos de altura, foi observado significativo aumento tanto no número de indivíduos $(48,46 \%)$ quanto no número de espécies $(22,22 \%)$, de 1997 para 2000 . A proporcionalidade NI/ NE em 1997 (30,89/1) e em 2000 (37,52/1) apresentou aumento de $21,47 \%$, refletindo a elevação da diversidade de espécies, expressa pelo índice de Shannon $\left(H^{\prime}\right)$ de

R. Árvore, Viçosa-MG, v.28, n.6, p.811-829, 2004 
2,850 em 1997 e de 2,977 em 2000, havendo, no entanto, queda da equabilidade, expressa pelo índice de Pielou (J), de 0,688 em 1997 para 0,674 em 2000.

As alterações observadas, tanto no número de indivíduos quanto no número de espécies por estrato por grupo ecológico e para a regeneração natural como um todo, foram estatisticamente significativas a $5 \%$ de probabilidade, pelo teste de $\chi^{2}$.

Os valores do índice de diversidade de Shannon (H') e do índice de equabilidade de Pielou (J), relativamente baixos nos dois inventários, e o grande aumento de densidade de indivíduos $(48,46 \%)$ e do número de espécies $(22,22 \%)$, evidenciaram um estágio inicial do processo de sucessão florestal em que o povoamento do Retiro-Branco se encontrava, ressaltando-se que, nos dois inventários, a faixa de inclusão de indivíduos foi ampla (>0,30 m de altura), o que permitiu uma varredura bastante completa dos componentes da diversidade.

As alterações observadas no índice de diversidade de Shannon (H'), nos estratos e regeneração natural como um todo, não foram significativas a $5 \%$ de probabilidade, pelo teste $t$, desenvolvido conforme Magurran (1988).

Quadro 2 - Diversidade florística da regeneração natural na área de Retiro-Branco, Poços de Caldas, MG. H' = índice de Shannon, $\mathrm{J}=$ índice de Equabilidade de Pielou, № E = número de espécies para a amostra e № I = número de indivíduos para a amostra

Table 2 - Species diversity for natural regeneration at Retiro-Branco, Poços de Caldas, Brazil. H'= Shannon Index, $J=$ Pielou Uniformity Index, № $E=$ number of species for sample and $N$ o $I=$ number of individuals for the sample

\begin{tabular}{|c|c|c|c|c|c|c|c|c|}
\hline \multirow[t]{3}{*}{ Regeneração Natural } & \multicolumn{8}{|c|}{ Diversidade Florística } \\
\hline & \multicolumn{4}{|c|}{1997} & \multicolumn{4}{|c|}{2000} \\
\hline & $\mathrm{H}^{\prime}$ & $\mathrm{J}$ & №E & №I & $\mathrm{H}^{\prime}$ & $\mathrm{J}$ & №E & №I \\
\hline Classe $1(0,30 \mathrm{~m}$ a $1,50 \mathrm{~m})$ & 2,938 & 0,733 & 55 & 1.404 & 2,936 & 0,691 & 70 & 2.038 \\
\hline Classe $2(1,51 \mathrm{~m}$ a $3,00 \mathrm{~m})$ & 2,278 & 0,657 & 32 & 389 & 2,693 & 0,725 & 41 & 471 \\
\hline Classe $3(>3,00 \mathrm{~m})$ & 1,958 & 0,706 & 16 & 153 & 2,015 & 0,605 & 28 & 380 \\
\hline RN Total & 2,850 & 0,688 & 63 & 1.946 & 2,927 & 0,674 & 77 & 2.889 \\
\hline
\end{tabular}

As diferenças entre os valores de índice de Shannon por classe de altura e para a regeneração natural total, entre 1997 e 2000 , não foram estatisticamente significativas a $5 \%$ de probabilidade, pelo teste $t$ aplicado conforme Magurran (1988).

Quadro 3 - Número de indivíduos, por grupo ecológico e por classe de diâmetro, no Retiro-Branco, Poços de Caldas, MG. $\mathrm{GE}=$ grupo ecológico, $\mathrm{N}$ o $\mathrm{I}=$ número de indivíduos para a amostra, $\mathrm{RN}=$ regeneração natural, $\mathrm{P}=$ pioneiras, $\mathrm{S}=$ secundárias e $\mathrm{C}=$ clímax

Table 3 - Number of individuals for ecological group and for diameter class, at Retiro-Branco, Poços de Caldas, Brazil $G E=$ ecological group; $N$ o $I=$ number of individuals for sample; $R N=$ natural regeneration; $P=$ pioneers; $S=$ secondary; and $C=$ climax

\begin{tabular}{|c|c|c|c|c|c|c|c|c|c|c|}
\hline \multicolumn{2}{|c|}{ Parâmetro } & \multirow{2}{*}{$\frac{\mathrm{GE}}{\mathrm{P}}$} & \multicolumn{2}{|c|}{ Classe 1} & \multicolumn{2}{|c|}{ Classe 2} & \multicolumn{2}{|c|}{ Classe 3} & \multicolumn{2}{|c|}{ RN Total } \\
\hline \multirow{8}{*}{ № I } & & & 393 & $(20,19 \%)$ & 108 & $(5,55 \%)$ & 49 & $(2,52 \%)$ & 550 & $(28,26 \%)$ \\
\hline & 1997 & $\mathrm{~S}$ & 615 & $(31,60 \%)$ & 186 & $(9,56 \%)$ & 60 & $(3,08 \%)$ & 861 & $(44,24 \%)$ \\
\hline & & $\mathrm{C}$ & 396 & $(20,35 \%)$ & 95 & $(4,88 \%)$ & 44 & $(2,26 \%)$ & 535 & $(27,49 \%)$ \\
\hline & & Total & 1.404 & $(72,14 \%)$ & 389 & $(19,99 \%)$ & 153 & $(7,86 \%)$ & 1.946 & $(100,0 \%)$ \\
\hline & & $\mathrm{P}$ & 701 & $(24,26 \%)$ & 134 & $(4,64 \%)$ & 109 & $(3,77 \%)$ & 944 & $(32,68 \%)$ \\
\hline & 2000 & $\mathrm{~S}$ & 603 & $(20,87 \%)$ & 206 & $(7,13 \%)$ & 184 & $(6,37 \%)$ & 993 & $(34,37 \%)$ \\
\hline & & $\mathrm{C}$ & 734 & $(25,41 \%)$ & 131 & $(4,53 \%)$ & 87 & $(3,01 \%)$ & 952 & $(32,95 \%)$ \\
\hline & & Total & 2.038 & $(70,54 \%)$ & 471 & $(16,30 \%)$ & 380 & $(13,15 \%)$ & 2.889 & $(100,0 \%)$ \\
\hline
\end{tabular}

As diferenças entre os números de indivíduos por grupo ecológico por classe de altura e total, entre 1997 e 2000 , foram estatisticamente significativas a $5 \%$ de probabilidade, pelo teste de qui-quadrado $\left(\chi^{2}\right)$.

R. Árvore, Viçosa-MG, v.28, n.6, p.811-829, 2004 


\subsection{Dinâmica da estrutura horizontal e vertical}

Os parâmetros quantitativos por espécies e por classe de altura da regeneração natural foram calculados nos dois inventários, 1997 e 2000 , de forma a permitir uma observação criteriosa das alterações ao longo do período de monitoramento, caracterizando-se a autoecologia das espécies e, assim, a dinâmica da regeneração natural do Retiro-Branco (Quadros 4, 5 e 6).

Os resultados apresentados no Quadro 3 indicam um aumento de 934 indivíduos, representando 48,46\% de aumento na densidade absoluta inicial da população arbóreo-arbustiva em regeneração natural no RetiroBranco. Na classe 1 de altura (entre $0,30 \mathrm{~m} \mathrm{e} 1,50 \mathrm{~m}$ ) houve um aumento de 634 (32,58\%) indivíduos na densidade absoluta, com a ressalva de que as pioneiras contribuíram com $308(15,83 \%)$, as secundárias com -12 (- 0,62\%) e as espécies clímax com 338 (17,37\%), destacando-se as espécies Psychotria sessilis com $263(13,51 \%)$ indivíduos, Baccharis semiserrata com 200 (10,28\%) indivíduos e Baccharis dracunculifolia com $76(3,91 \%)$ indivíduos. Na classe 2 de altura, o aumento da densidade absoluta foi de $82(4,21 \%)$ indivíduos, em que as pioneiras contribuíram com 26 $(1,34 \%)$, as secundárias com $20(1,03 \%)$ e as clímax com $36(1,85 \%)$, destacando-se as espécies Miconia pepericarpa com 26 (1,34\%), Leandra melastomoides com $16(0,82 \%)$ e Leandra lacunosa com 14 (0,72\%). Na classe 3 de altura, a densidade absoluta cresceu de $227(11,66 \%)$ indivíduos, tendo as pioneiras contribuído com $60(3,08 \%)$ indivíduos, as secundárias com 124 $(6,37 \%)$ e as clímax com $43(2,21 \%)$, destacando-se as espécies Miconia sellowiana com 113 (5,81\%) indivíduos, Clethra scabra com 33 (1,70\%) e Psychotria sessilis com $19(0,98 \%)$. As diferenças foram estatisticamente significativas a $5 \%$ de probabilidade, pelo teste de qui-quadrado $\left(\chi^{2}\right)$.

O total de indivíduos mortos foi de 632 , representando $32,48 \%$ do total de indivíduos observados em 1997, ressaltando-se que, desse total, na classe 1 foram $562(28,88 \%)$, dos quais $168(8,68 \%)$ pertencentes a espécies pioneiras, $265(13,62 \%)$ a espécies secundárias e $128(6,58 \%)$ a espécies clímax, com destaque para Leandra lacunosa com 94 (4,83\%), Miconia sellowiana com 87 (4,47\%) e Psychotria sessilis com 65 (3,34\%), na classe 2 foram 258 (2,98\%) indivíduos mortos, dos quais $13(0,67 \%)$ pertencentes a espécies pioneiras, $32(1,64 \%)$ a secundárias e $13(0,67 \%)$ a clímax, destacando-se Leandra melastomoides com 18 (0,92\%), Miconia sellowiana com $14(0,72 \%)$ e Psychotria sessilis com $10(0,51 \%)$; e na classe 3 foram $12(0,62 \%)$ indivíduos mortos, dos quais cinco $(0,26 \%)$ pertencentes a espécies pioneiras, $3(0,15 \%)$ a secundárias e $4(0,21 \%)$ a clímax, destacando-se Psychotria sessilis com 3 (0,15\%), Baccharis dracunculifolia com $3(0,15 \%)$ e Miconia sellowiana com $1(0,05 \%)$.

O total de indivíduos que ingressaram foi de 1.564, representando $80,37 \%$ do total daqueles observados em 1997, estando distribuídos da seguinte forma: na classe 1 foram $1.487(76,41 \%)$, dos quais $559(28,73 \%)$ pertencentes a espécies pioneiras, $392(20,14 \%)$ pertencentes a secundárias e $536(27,54 \%)$ a clímax, destacando-se Psychotria sessilis com 351 (18,04\%) indivíduos, Baccharis semiserrata com 231 (11,87\%) e Miconia sellowiana com 132 (6,78\%); na classe 2 foram $72(3,70 \%)$ indivíduos, dos quais $21(1,08 \%)$ pertencentes a espécies pioneiras, $30(1,54 \%)$ a secundárias e $21(1,08 \%)$ a clímax, destacando-se as espécies Leandra melastomoides com 14 (0,72\%), Miconia pepericarpa com 11 (0,67\%) e Miconia sellowiana com $11(0,57 \%)$; e na classe 3 foram cinco $(0,26 \%)$ indivíduos, dos quais dois $(0,10 \%)$ pertencentes a secundárias e três $(0,16 \%)$ a clímax, sendo Miconia sellowiana com $2(0,10 \%)$, Psychotria sessilis com $2(0,10 \%)$ e Myrsine umbellata com 1 (0,06\%).

Os indivíduos emigrantes, ou seja, os que passaram de uma classe de altura para a seguinte, totalizaram 466 , representando $23,84 \%$ do número de indivíduos iniciais, em que da classe 1 emigraram $282(14,49 \%)$ indivíduos, dos quais $80(4,11 \%)$ de espécies pioneiras, $134(6,89 \%)$ de secundárias e 68 (3,49\%) de clímax, destacando-se as espécies Miconia sellowiana (secundária) com 83 (4,27\%) emigrantes, Clethra scabra (pioneira) com $32(1,64 \%)$ e Leandra melastomoides (secundária) com $23(1,19 \%)$; e da classe 2 emigraram $182(9,35 \%)$ indivíduos, dos quais $50(2,57 \%)$ pioneiras, 94 (4,83\%) secundárias e 38 (1,95\%) clímax, destacandose as espécies Miconia sellowiana com 88 (4,5\%) emigrantes, Clethra scabra com 30 (1,54\%) e Psychotria sessilis (clímax) com 20 (1,03\%).

O crescimento em área basal observado foi de 1,012 $\mathrm{m}^{2}\left(10,65 \mathrm{~m}^{2} / \mathrm{ha}\right)$ entre $1997\left(7,89 \mathrm{~m}^{2} / \mathrm{ha}\right)$ e $2000(18,62$ $\left.\mathrm{m}^{2} / \mathrm{ha}\right)$. Em relação às classes de altura e aos grupos ecológicos, este crescimento está assim distribuído: na classe 1 o crescimento foi de $0,39 \mathrm{~m}^{2} / \mathrm{ha}(4,90 \%)$,

R. Árvore, Viçosa-MG, v.28, n.6, p.811-829, 2004 
com a ressalva de que as espécies pioneiras contribuíram com $0,12 \mathrm{~m}^{2} / \mathrm{ha}(1,55 \%)$, as secundárias com $0,06 \mathrm{~m}^{2} / \mathrm{ha}(0,79 \%)$ e as clímax com $0,20 \mathrm{~m}^{2} / \mathrm{ha}$ $(2,55 \%)$, destacando-se o crescimento líquido das espécies Psychotria sessilis com $0,09 \mathrm{~m}^{2} / \mathrm{ha}(1,14 \%)$, Solanum robustum com $0,08 \mathrm{~m}^{2} / \mathrm{ha}(1,01 \%)$ e Miconia pepericarpa com $0,07 \mathrm{~m}^{2} / \mathrm{ha}(0,89 \%)$; na classe 2 , o crescimento foi de $0,25 \mathrm{~m}^{2} / \mathrm{ha}(3,21 \%)$, em que as pioneiras contribuíram com $-0,06 \mathrm{~m}^{2} / \mathrm{ha}(-0,79 \%)$, as secundárias com $0,05 \mathrm{~m}^{2} / \mathrm{ha}(0,66 \%)$ e as clímax com $0,26 \mathrm{~m}^{2} / \mathrm{ha}(3,35 \%)$, destacando-se as espécies Miconia pepericarpa com $0,21 \mathrm{~m}^{2} / \mathrm{ha}(2,66 \%)$, Leandra melastomoides com $0,08 \mathrm{~m}^{2} / \mathrm{ha}(1,01 \%)$ e Tibouchina candolleana com $0,06 \mathrm{~m}^{2} / \mathrm{ha}(0,76 \%)$; na classe 3 , o crescimento foi de $10,01 \mathrm{~m}^{2} /$ ha $(126,91 \%)$, tendo as espécies pioneiras contribuído com $3,15 \mathrm{~m}^{2} / \mathrm{ha}$ $(39,92 \%)$, as secundárias com $5,36 \mathrm{~m}^{2} /$ ha $(67,89 \%)$ e as clímax com $1,51 \mathrm{~m}^{2} / \mathrm{ha}(19,19 \%)$, destacandose as espécies com maior crescimento líquido Miconia sellowiana com $5,06 \mathrm{~m}^{2} / \mathrm{ha}(64,13 \%)$, Clethra scabra com $1,35 \mathrm{~m}^{2} /$ ha $(17,11 \%)$ e Myrsine umbellata com $0,75 \mathrm{~m}^{2} / \mathrm{ha}(9,51 \%)$.

Quadro 4 - Dinâmica quantitativa dos parâmetros da classe 1 de altura da regeneração natural no Retiro-Branco, em Poços de Caldas, MG. №I = número de indivíduos, IVI = índice de valor de importância, RNCij = regeneração natural, $\mathrm{M}=$ mortalidade, $\mathrm{TM}=$ taxa de mortalidade $(\%), \mathrm{I}=$ ingresso, $\mathrm{TI}=$ taxa de ingresso (\%), IPA = incremento periódico anual $(\mathrm{mm} / \mathrm{ano}), \mathrm{CB}=$ crescimento bruto $\left(\mathrm{m}^{2} / \mathrm{ha}\right)$ e $\mathrm{AB}=$ área basal

Table 4 - Quantitative dynamics for parameters of Class 1 of natural regeneration at Retiro-Branco, Poços de Caldas, Brazil. $N$ No $=$ number of individuals, $I V I=$ importance value index, $R N C i j=$ natural regeneration, $M=$ mortality, $T M=$ mortality rate $(\%), I=$ ingrowth,$T I=$ ingrowth rates $(\%), I P A=$ annual increase $(\mathrm{mm} /$ year $), C B=$ growth $\left(m^{2} / h a\right)$ and $A B=$ basal area

\begin{tabular}{|c|c|c|c|c|c|c|c|c|c|c|c|c|}
\hline \multirow[t]{2}{*}{ ESPÉCIE } & \multicolumn{3}{|c|}{1997} & \multicolumn{3}{|c|}{2000} & \multirow[t]{2}{*}{$\mathrm{TM}_{\mathrm{ij}}$} & \multirow[t]{2}{*}{$\mathrm{M}_{\mathrm{AB}}$} & \multirow[t]{2}{*}{$\mathrm{TI}_{\mathrm{ij}}$} & \multirow[t]{2}{*}{$\mathrm{I}_{\mathrm{AB}}$} & \multirow[t]{2}{*}{ IPA } & \multirow[t]{2}{*}{$\mathrm{CB}$} \\
\hline & №I & IVI & $\mathrm{RNC}_{\mathrm{ij}}$ & №I & IVI & $\mathrm{RNC}_{\mathrm{ij}}$ & & & & & & \\
\hline Miconia sellowiana & 267 & 44,71 & 8,68 & 224 & 33,39 & 5,31 & 32,58 & 0,003518 & 58,93 & 0,007805 & 2,08 & 0,006368 \\
\hline Psychotria sessilis & 171 & 27,83 & 5,83 & 434 & 41,86 & 8,95 & 38,01 & 0,002809 & 80,88 & 0,009763 & 1,65 & 0,011359 \\
\hline Leandra melastomoides & 113 & 21,20 & 4,53 & 118 & 15,75 & 3,32 & 54,87 & 0,004242 & 76,27 & 0,003419 & 1,92 & 0,003577 \\
\hline Clethra scabra & 75 & 26,49 & 3,08 & 57 & 16,40 & 1,89 & 9,33 & 0,000713 & 38,60 & 0,002015 & 2,30 & $-0,002612$ \\
\hline Baccharis semiserrata & 41 & 8,00 & 2,30 & 241 & 18,31 & 4,93 & 75,61 & 0,000898 & 95,85 & 0,004263 & 1,41 & 0,004413 \\
\hline Myrsine umbellata & 64 & 13,67 & 3,28 & 74 & 11,93 & 2,64 & 34,38 & 0,000781 & 62,16 & 0,002120 & 1,70 & 0,001446 \\
\hline Miconia pepericarpa & 93 & 17,81 & 4,02 & 96 & 19,63 & 3,02 & 29,03 & 0,000790 & 52,08 & 0,004100 & 2,51 & 0,007440 \\
\hline Leandra lacunosa & 156 & 20,14 & 5,83 & 152 & 16,51 & 3,99 & 60,26 & 0,001711 & 67,11 & 0,002116 & 1,39 & 0,003801 \\
\hline Baccharis dracunculifolia & 25 & 6,29 & 1,60 & 101 & 11,11 & 2,73 & 56,00 & 0,000685 & 94,06 & 0,002963 & 1,62 & 0,002585 \\
\hline Tibouchina candolleana & 42 & 12,66 & 2,42 & 39 & 8,46 & 1,65 & 26,19 & 0,000620 & 56,41 & 0,000796 & 1,78 & $-0,000520$ \\
\hline Mimosa scabrella & 57 & 8,57 & 2,52 & 51 & 6,90 & 1,86 & 78,95 & 0,000693 & 92,16 & 0,000927 & 1,42 & 0,000788 \\
\hline Ocotea pulchella & 23 & 6,13 & 1,65 & 60 & 8,86 & 2,02 & 21,74 & 0,000119 & 78,33 & 0,001384 & 1,94 & 0,002019 \\
\hline Casearia sylvestris & 23 & 6,81 & 1,93 & 24 & 6,17 & 1,47 & 21,74 & 0,000151 & 37,50 & 0,000421 & 1,53 & 0,000911 \\
\hline Blepharocalyx salicifolius & 33 & 7,32 & 1,42 & 55 & 6,94 & 1,40 & 24,24 & 0,001030 & 63,64 & 0,001280 & 1,57 & 0,001315 \\
\hline Alchornea triplinervia & 10 & 3,70 & 0,93 & 23 & 5,74 & 1,30 & 40,00 & 0,000130 & 86,96 & 0,001344 & 2,71 & 0,001080 \\
\hline Cordia superba & 22 & 8,23 & 1,62 & 11 & 3,96 & 0,64 & 40,91 & 0,000936 & 27,27 & 0,000097 & 2,15 & 0,000176 \\
\hline Myrcia rostrata & 16 & 4,73 & 1,18 & 18 & 4,00 & 0,91 & 12,50 & 0,000102 & 44,44 & 0,000182 & 1,37 & 0,000197 \\
\hline Cestrum amictum & 11 & 3,21 & 0,95 & 13 & 3,23 & 0,75 & 81,82 & 0,000203 & 92,31 & 0,000774 & 2,38 & 0,000773 \\
\hline Aureliana velutina & 0 & 0,00 & 0,00 & 23 & 4,44 & 1,15 & 0,00 & 0,000000 & 100,00 & 0,000773 & 1,94 & 0,000760 \\
\hline Siphoneugena densiflora & 8 & 3,00 & 0,78 & 23 & 4,88 & 1,15 & 25,00 & 0,000126 & 78,26 & 0,000668 & 2,09 & 0,000886 \\
\hline Vernonia westiniana & 19 & 4,35 & 1,16 & 15 & 2,99 & 0,71 & 42,11 & 0,000349 & 46,67 & 0,000150 & 1,22 & 0,000349 \\
\hline Cupania vernalis & 5 & 2,05 & 0,61 & 16 & 3,80 & 0,95 & 20,00 & 0,000013 & 75,00 & 0,000485 & 1,85 & 0,000583 \\
\hline Myrcia formosiana & 4 & 1,51 & 0,39 & 15 & 4,08 & 0,94 & 0,00 & 0,000000 & 73,33 & 0,000461 & 2,18 & 0,000855 \\
\hline Vernonia ferruginea & 0 & 0,00 & 0,00 & 1 & 0,33 & 0,09 & 0,00 & 0,000000 & 100,00 & 0,000020 & 1,67 & 0,000019 \\
\hline Eupatorium inulaefolium & 23 & 4,15 & 1,17 & 8 & 1,65 & 0,44 & 78,26 & 0,000431 & 62,50 & 0,000057 & 1,08 & 0,000051 \\
\hline Baccharis punctulata & 8 & 2,25 & 0,69 & 22 & 2,75 & 0,68 & 25,00 & 0,000035 & 81,82 & 0,000466 & 1,71 & 0,000605 \\
\hline Pimenta pseudocaryophyllus & 3 & 1,61 & 0,37 & 10 & 2,26 & 0,63 & 0,00 & 0,000000 & 80,00 & 0,000145 & 1,40 & $-0,000285$ \\
\hline
\end{tabular}

R. Árvore, Viçosa-MG, v.28, n.6, p.811-829, 2004 
Quadro 4 - cont.

Table 4 - cont.

\begin{tabular}{|c|c|c|c|c|c|c|c|c|c|c|c|c|}
\hline \multirow[t]{2}{*}{ ESPÉCIE } & \multicolumn{3}{|c|}{1997} & \multicolumn{3}{|c|}{2000} & \multirow[t]{2}{*}{$\mathrm{TM}_{\mathrm{ij}}$} & \multirow[t]{2}{*}{$\mathrm{M}_{\mathrm{AB}}$} & \multirow[t]{2}{*}{$\mathrm{TI}_{\mathrm{ij}}$} & \multirow[t]{2}{*}{$\mathrm{I}_{\mathrm{AB}}$} & \multirow[t]{2}{*}{ IPA } & \multirow[t]{2}{*}{$\mathrm{CB}$} \\
\hline & NoI & IVI & $\overline{\mathrm{RNC}_{\mathrm{ij}}}$ & NoI & IVI & $\mathrm{RNC}_{\mathrm{ij}}$ & & & & & & \\
\hline Cordia ecalyculata & 0 & 0,00 & 0,00 & 10 & 2,49 & 0,70 & 0,00 & 0,000000 & 100,00 & 0,000160 & 1,47 & 0,000190 \\
\hline Casearia decandra & 7 & 2,45 & 0,56 & 5 & 0,98 & 0,19 & 28,57 & 0,000161 & 60,00 &, 000130 & 1,73 & $-0,000124$ \\
\hline Schefflera angustissima & 3 & 1,46 & 0,37 & 6 & 2,15 & 0,48 & 33,33 & 0,000038 & 83,33 & 0,000589 & 3,11 & 0,000418 \\
\hline Myrciaria tenella & 11 & 3,11 & 0,86 & 9 & 2,66 & 0,53 & 27,27 & 0,000045 & 11,11 & 0,000079 & 1,74 & 0,000615 \\
\hline Vernonia polyanthes & 3 & 1,16 & 0,37 & 2 & 0,65 & 0,19 & 100,00 & 0,000035 & 100,00 & 0,000020 & 1,17 & 0,000016 \\
\hline Myrcia tomentosa & 5 & 2,22 & 0,51 & 4 & 1,96 & 0,37 & 40,00 & 0,000114 & 50,00 & 0,000083 & 2,00 & 0,000399 \\
\hline Gomidesia anacardiaefolia & 4 & 1,71 & 0,39 & 3 & 1,14 & 0,28 & 25,00 & 0,000020 & 66,67 & 0,000102 & 1,78 & $-0,000170$ \\
\hline Roupala brasiliensis & 6 & 2,12 & 0,54 & 3 & 0,54 & 0,13 & 0,00 & 0,000000 & 0,00 & 0,000000 & 1,22 & $-0,000190$ \\
\hline Alibertia concolor & 4 & 1,41 & 0,39 & 5 & 1,52 & 0,31 & 0,00 & 0,000000 & 20,00 & 0,000113 & 2,20 & 0,000380 \\
\hline Cybianthus cuneifolius & 6 & 0,79 & 0,25 & 10 & 1,55 & 0,40 & 16,67 & 0,000007 & 50,00 & 0,000143 & 1,47 & 0,000197 \\
\hline Daphnopsis fasciculata & 4 & 1,40 & 0,39 & 4 & 1,11 & 0,30 & 0,00 & 0,000000 & 25,00 & 0,000007 & 0,67 & $-0,000095$ \\
\hline Voch & 2 & 1,28 & 0,24 & 1 & 0,51 & 0,09 & 0,00 & 0,000000 & 0,00 & 0,000000 & 2,00 & $-0,000285$ \\
\hline Zanth & 3 & 1,45 & 0,37 & 1 & 0,38 & 0,09 & 0,00 & 0,000000 & 0,00 & 0,000000 & 1,00 & $-0,000190$ \\
\hline Miconia albicans & 1 & 0,38 & 0,12 & 1 & 0,35 & 0,09 & 0,00 & 0,000000 & 0,00 & 0,000000 & 1,00 & 0,000029 \\
\hline binthifolius & 0 & 0,00 & 0,00 & 3 & 1,03 & 0,28 & 0,00 & 0,000000 & 100,00 & 0,000096 & 2,00 & 0,000095 \\
\hline Senna bicapsularis & 3 & 1,18 & 0,37 & 3 & 1,03 & 0,28 & 0,00 & 0,000000 & 0,00 & 0,000000 & 0,56 & 0,000000 \\
\hline Baccharis serrulata & 5 & 1,61 & 0,42 & 7 & 1,13 & 0,27 & 80,00 & 0,000240 & 85,71 & 0,000245 & 1,90 & 0,000240 \\
\hline Pera obovata & 3 & 1,10 & 0,17 & 1 & 0,44 & 0,09 & 0,00 & 0,000000 & 0,00 & 0,000000 & 2,00 & $-0,000380$ \\
\hline Prunus myrtifolia & 1 & 0,38 & 0,12 & 3 & 0,74 & 0,20 & 0,00 & 0,000000 & 66,67 & 0,000020 & 1,22 & 0,000086 \\
\hline Xylosma pseudosalzmannii & 0 & 0,00 & 0,00 & 0 & 0,00 & 0,00 & 0,00 & 0,000000 & 0,00 & 0,000000 & 0,00 & 0,000000 \\
\hline Byrsonima sp. & 0 & 0,00 & 0,00 & 2 & 0,78 & 0,19 & 0,00 & 0,000000 & 100,00 & 0,000182 & 3,33 & 0,000190 \\
\hline Cabralea canjerana & 3 & 1,47 & 0,37 & 2 & 0,98 & 0,19 & 33,33 & 0,000095 & 0,00 & 0,000000 & 1,17 & 0,000190 \\
\hline Erythroxylum deciduv & 4 & 1,11 & 0,29 & 2 & 0,73 & 0,19 & 50,00 & 0,000098 & 0,00 & 0,000000 & 0,17 & 0,000003 \\
\hline Rubus brasiliensis & 3 & 0,55 & 0,17 & 1 & 0,35 & 0,09 & 66,67 & 0,000025 & 0,00 & 0,000000 & 1,33 & 0,000035 \\
\hline Sapium glandulatum & 1 & 0,44 & 0,12 & 1 & 0,37 & 0,09 & 0,00 & 0,000000 & 0,00 & 0,000000 & 0,00 & 0,000000 \\
\hline Maytenus salicifolia & 0 & 0,00 & 0,00 & 1 & 0,33 & 0,09 & 0,00 & 0,000000 & 100,00 & 0,000020 & 1,67 & 0,000019 \\
\hline Alomia fastigiata & 1 & 0,46 & 0,1 & 3 & 0,57 & 0,13 & 100,00 & 0,000079 & 100,00 & 0,000186 & 2,78 & 0,000174 \\
\hline Pipersp. & 0 & 0,00 & 0,0 & 3 & 0,42 & 0,13 & 0,00 & 0,000000 & 100,00 & 0,000013 & 0,78 & 0,000010 \\
\hline Tabebuia alba & 0 & 0,00 & 0,0 & 2 & 0,40 & 0,11 & 0,00 & 0,000000 & 100,00 & 0,000046 & 1,67 & 0,000095 \\
\hline Trichilia silvatica & 0 & 0,00 & 0,0 & 2 & 0,48 & 0,11 & 0,00 & 0,000000 & 100,00 & 0,000134 & 3,00 & 0,000095 \\
\hline Solc & 0 & 0,00 & 0,0 & 0 & 0,00 & 0,00 & 0,00 & 0,000000 & 0,00 & 0,000000 & 0,00 & 0,000000 \\
\hline robustum & 0 & 0,00 & 0,0 & 1 & 0,39 & 0,09 & 0,00 & 0,000000 & 100,00 & 0,000095 & 3,67 & 0,007600 \\
\hline Ani & 0 & 0,00 & 0, & 0 & 0,00 & 0,00 & 0,00 & 0,0 & 0,00 & 0,0 & 0,00 & 0,000000 \\
\hline Trembleya pa & 0 & 0,00 & 0,00 & 0 & 0,00 & 0,00 & 0,00 & 0,000000 & 0,00 & 0,000000 & 0,00 & 0,000000 \\
\hline Rubiaceae 1 & 0 & 0,00 & 0,00 & 0 & 0,00 & 0,00 & 0,00 & 0,000000 & 0,00 & 0,000000 & 0,00 & 0,000000 \\
\hline Lamanonia ternata & 0 & 0,00 & 0,00 & 0 & 0,00 & 0,00 & 0,00 & 0,000000 & 0,00 & 0,000000 & 0,00 & 0,000000 \\
\hline Machaerium nyctitans & 1 & 0,41 & 0,12 & 1 & 0,41 & 0,09 & 0,00 & 0,000000 & 0,00 & 0,000000 & 1,67 & 0,000057 \\
\hline Myrsine gardneriana & 0 & 0,00 & 0,00 & 1 & 0,35 & 0,09 & 0,00 & 0,000000 & 100,00 & 0,000038 & 2,33 & 0,000038 \\
\hline Alibertia sessilis & 0 & 0,00 & 0,00 & 1 & 0,33 & 0,09 & 0,00 & 0,000000 & 100,00 & 0,000020 & 1,67 & 0,000019 \\
\hline Solanum swartzianum & 0 & 0,00 & 0,00 & 1 & 0,33 & 0,09 & 0,00 & 0,000000 & 100,00 & 0,000020 & 1,67 & 0,000019 \\
\hline Astronium graveolens & 0 & 0,00 & 0,0 & 1 & 0,32 & 0,09 & 0,00 & 0,000000 & 100,00 & 0,000007 & 1,00 & 0,000010 \\
\hline$M a$ & 1 & 0,38 & 0, & 1 & 0,33 & 0,09 & 0,00 & 0,000000 & 0,00 & 0,000000 & 0,33 & 0,000010 \\
\hline Prokia crucis & 0 & 0,00 & 0,0 & 1 & 0,32 & 0,09 & 0,00 & 0,000000 & 100,00 & 0,000007 & 1,00 & 0,000010 \\
\hline Cedrela fissilis & 1 & & & 1 & & & 0,00 & & 0,00 & 0,000000 & 0,00 & 0,000000 \\
\hline Cryptocarya asch & 1 & & & 1 & & & 0,00 & & 0,00 & 0,000000 & 0,00 & 0,000000 \\
\hline Eupatorium sp, & 1 & 0,60 & 0,1 & 1 & 0,51 & 0,09 & 0,00 & & 0,00 & 0,000000 & 0,33 & 0,00000 \\
\hline Hovenia dulcis & 1 & 0,41 & 0,1 & 1 & 0,35 & 0,09 & 0,00 & 0,000000 & 0,00 & 0,000000 & 0,00 & 0,00000 \\
\hline Matayba juglandifolia & 1 & 0,46 & 0,12 & 1 & 0,43 & 0,09 & 0,00 & 0,000000 & 0,00 & 0,000000 & 1,00 & 0,000000 \\
\hline Myrsine lancifolia & 2 & 0,77 & 0,24 & 1 & 0,33 & 0,09 & 50,00 & 0,000013 & 0,00 & 0,000000 & 0,67 & 0,000013 \\
\hline Psidium cinereum & 0 & 0,00 & 0,00 & 0 & 0,00 & 0,00 & 0,00 & 0,000000 & 0,00 & 0,000000 & 0,00 & 0,00000 \\
\hline
\end{tabular}


Quadro 5 - Dinâmica quantitativa dos parâmetros da classe 2 de altura da regeneração natural no Retiro-Branco, em Poços de Caldas, MG. №I = número de indivíduos, IVI = índice de valor de importância, $\mathrm{RNCij}=$ regeneração natural, $\mathrm{M}=$ mortalidade, $\mathrm{TM}=$ taxa de mortalidade $(\%), \mathrm{I}=$ ingresso, $\mathrm{TI}=$ taxa de ingresso $(\%), \mathrm{IPA}=$ incremento periódico anual $(\mathrm{mm} / \mathrm{ano}), \mathrm{CB}=$ crescimento bruto $\left(\mathrm{m}^{2} / \mathrm{ha}\right)$, e $\mathrm{AB}=$ área basal

Table 5 - Quantitative dynamics for parameters of Class 2 of natural regeneration at Retiro-Branco, Poços de Caldas, Brazil. № $I=$ number of individuals, $I V I=$ importance value index, $R N C i j=$ natural regeneration, $M=$ mortality, $T M=$ mortality rate $(\%), I=$ ingrowth, $T I=$ ingrowth rates $(\%), I P A=$ annual increase $(\mathrm{mm} /$ year $), C B=$ growth $\left(m^{2} / h a\right), A B=$ basal area

\begin{tabular}{|c|c|c|c|c|c|c|c|c|c|c|c|c|}
\hline \multirow[t]{2}{*}{ ESPÉCIE } & \multicolumn{3}{|c|}{1997} & \multicolumn{3}{|c|}{2000} & \multirow[t]{2}{*}{$\mathrm{TM}_{\mathrm{ij}}$} & \multirow[t]{2}{*}{$\mathrm{M}_{\mathrm{AB}}$} & \multirow[t]{2}{*}{$\mathrm{TI}_{\mathrm{ij}}$} & \multirow[t]{2}{*}{$\mathrm{I}_{\mathrm{AB}}$} & \multirow[t]{2}{*}{ IPA } & \multirow[t]{2}{*}{$\mathrm{CB}$} \\
\hline & $\mathrm{N} N$ & IVI & $\overline{\mathrm{RNC}_{\mathrm{ij}}}$ & NoI & IVI & $\mathrm{RNC}_{\mathrm{ij}}$ & & & & & & \\
\hline Miconia sellowiana & 133 & 80,88 & 4,95 & 109 & 59,69 & 3,32 & 10,53 & 0,007325 & 10,09 & 0,003479 & 4,70 & $-0,00580$ \\
\hline Psychotria sessilis & 47 & 29,88 & 2,78 & 46 & 26,98 & 1,63 & 21,28 & 0,008342 & 13,04 & 0,001898 & 3,15 & 0,006793 \\
\hline Leandra melastomoides & 42 & 32,28 & 2,36 & 58 & 30,27 & 1,98 & 42,86 & 0,008324 & 24,14 & 0,005468 & 4,06 & 0,016171 \\
\hline Clethra scabra & 56 & 45,29 & 2,13 & 55 & 36,58 & 1,78 & 3,57 & 0,001063 & 5,45 & 0,001209 & 3,44 & 0,002992 \\
\hline Baccharis semiserrata & 2 & 3,00 & 0,24 & 8 & 4,49 & 0,44 & 50,00 & 0,001257 & 87,50 & 0,001074 & 3,88 & 0,001105 \\
\hline Myrsine umbellata & 26 & 17,58 & 1,44 & 28 & 17,05 & 1,31 & 3,85 & 0,000201 & 14,29 & 0,002350 & 3,15 & 0,002006 \\
\hline Miconia pepericarpa & 15 & 13,47 & 1,25 & 41 & 26,22 & 1,69 & 13,33 & 0,000531 & 26,83 & 0,003409 & 4,94 & 0,020823 \\
\hline Leandra lacunosa & 0 & 0,00 & 0,00 & 14 & 8,79 & 0,85 & 0,00 & 0,000000 & 14,29 & 0,000419 & 3,48 & 0,003145 \\
\hline Baccharis dracunculifolia & 7 & 9,14 & 0,24 & 7 & 5,56 & 0,57 & 57,14 & 0,004030 & 42,86 & 0,000557 & 3,24 & $-0,000331$ \\
\hline Tibouchina candolleana & 15 & 11,00 & 0,87 & 21 & 15,81 & 1,19 & 20,00 & 0,000945 & 4,76 & 0,000661 & 3,13 & 0,006607 \\
\hline Mimosa scabrella & 2 & 1,67 & 0,15 & 5 & 3,66 & 0,39 & 0,00 & 0,000000 & 20,00 & 0,000095 & 3,13 & $-0,000086$ \\
\hline Ocotea pulchella & 3 & 3,40 & 0,37 & 6 & 4,20 & 0,41 & 0,00 & 0,000000 & 0,00 & 0,000000 & 2,33 & 0,000770 \\
\hline Casearia sylvestris & 3 & 3,53 & 0,37 & 5 & 4,51 & 0,46 & 0,00 & 0,000000 & 0,00 & 0,000000 & 2,40 & $-0,000038$ \\
\hline Blepharocalyx salicifolius & 3 & 4,34 & 0,37 & 12 & 7,37 & 0,66 & 0,00 & 0,000000 & 8,33 & 0,000113 & 1,39 & 0,001653 \\
\hline Alchornea triplinervia & 1 & 1,21 & 0,12 & 3 & 3,27 & 0,28 & 0,00 & 0,000000 & 0,00 & 0,000000 & 5,11 & 0,001967 \\
\hline Cordia superba & 3 & 3,81 & 0,37 & 8 & 7,49 & 0,67 & 0,00 & 0,000000 & 12,50 & 0,000039 & 2,63 & 0,001805 \\
\hline Myrcia rostrata & 2 & 2,53 & 0,24 & 6 & 5,68 & 0,56 & 0,00 & 0,000000 & 66,67 & 0,000000 & 1,67 & 0,001511 \\
\hline Cestrum amictum & 3 & 3,03 & 0,24 & 2 & 1,90 & 0,19 & 33,33 & 0,000154 & 0,00 & 0,000000 & 2,17 & 0,000420 \\
\hline Aureliana velutina & 0 & 0,00 & 0,00 & 2 & 1,07 & 0,11 & 0,00 & 0,000000 & 100,00 & 0,000177 & 3,50 & 0,000181 \\
\hline Siphoneugena densiflora & 0 & 0,00 & 0,00 & 1 & 1,08 & 0,09 & 0,00 & 0,000000 & 0,00 & 0,000000 & 4,67 & 0,000751 \\
\hline Vernonia westiniana & 2 & 2,19 & 0,24 & 3 & 2,14 & 0,20 & 50,00 & 0,000154 & 0,00 & 0,000000 & 3,78 & 0,000866 \\
\hline Cupania v & 0 & 0,00 & 0,00 & 0 & 0,00 & 0,00 & 0,00 & 0,000000 & 0,00 & 0,000000 & 0,00 & 0,000000 \\
\hline Myrcia formosiana & 0 & 0,00 & 0,00 & 0 & 0,00 & 0,00 & 0,00 & 0,000000 & 0,00 & 0,000000 & 0,00 & 0,000000 \\
\hline Vernonia ferruginea & 2 & 6,77 & 0,27 & 1 & 1,10 & 0,09 & 0,00 & 0,000000 & 100,00 & 0,000804 & 10,67 & $-0,001283$ \\
\hline Eupatorium inulaefolium & 0 & 0,00 & 0,00 & 2 & 1,85 & 0,19 & 0,00 & 0,000000 & 0,00 & 0,000000 & 3,67 & 0,000713 \\
\hline Baccharis punctulata & 0 & 0,00 & 0,00 & 2 & 1,06 & 0,11 & 0,00 & 0,000000 & 0,00 & 0,000000 & 0,83 & 0,000143 \\
\hline Pimenta pseudocaryophyllus & 0 & 0,00 & 0,00 & 1 & 1,04 & 0,09 & 0,00 & 0,000000 & 0,00 & 0,000000 & 2,00 & 0,000665 \\
\hline Cordia ec & 0 & 0,00 & 0,00 & 0 & 0,00 & 0,00 & 0,00 & 0,000000 & 0,00 & 0,000000 & 0,00 & 0,000000 \\
\hline Caseariad & 2 & 2,73 & 0,27 & 4 & 2,64 & 0,22 & 0,00 & 0,000000 & 0,00 & 0,000000 & 2,83 & 0,000884 \\
\hline Schefflera & 0 & 0,00 & 0,00 & 0 & 0,00 & 0,00 & 0,00 & 0,000000 & 0,00 & 0,000000 & 0,00 & 0,000000 \\
\hline Myrciaria tenella & 0 & 0,00 & 0,00 & 0 & 0,00 & 0,00 & 0,00 & 0,000000 & 0,00 & 0,000000 & 0,00 & 0,000000 \\
\hline Vernonia polyanthes & 6 & 6,36 & 0,63 & 2 & 1,06 & 0,11 & 0,00 & 0,000000 & 100,00 & 0,000145 & 3,17 & $-0,010783$ \\
\hline Gomidesia anacardiaefolia & 0 & 0,00 & 0,00 & 1 & 0,93 & 0,09 & 0,00 & 0,000000 & 0,00 & 0,000000 & 3,33 & 0,000380 \\
\hline Myrcia tomentosa & 0 & 0,00 & 0,00 & 1 & 1,08 & 0,09 & 0,00 & 0,000000 & 100,00 & 0,000000 & 8,33 & 0,000751 \\
\hline Roupala brasiliensis & 0 & 0,00 & 0,00 & 3 & 2,75 & 0,28 & 0,00 & 0,000000 & 0,00 & 0,000000 & 2,78 & 0,000998 \\
\hline Alibertia concolor & 1 & 1,15 & 0,12 & 1 & 0,89 & 0,09 & 0,00 & 0,000000 & 0,00 & 0,000000 & 0,67 & 0,000067 \\
\hline Cybianthus & 0 & 0,00 & 0,00 & 0 & 0,00 & 0,00 & 0,00 & 0,000000 & 0,00 & 0,000000 & 0,00 & 0,000000 \\
\hline Daphnopsis fasciculata & 0 & 0,00 & 0,00 & 1 & 0,89 & 0,09 & 0,00 & 0,000000 & 0,00 & 0,000000 & 2,00 & 0,000257 \\
\hline Vochysia tucanorum & 0 & 0,00 & 0,00 & 0 & 0,00 & 0,00 & 0,00 & 0,000000 & 0,00 & 0,000000 & 0,00 & 0,000000 \\
\hline Zanthoxylum rhoifolium & 1 & 1,29 & 0,12 & 2 & 2,24 & 0,19 & 0,00 & 0,000000 & 0,00 & 0,000000 & 6,67 & 0,001140 \\
\hline Miconia albicans & 3 & 2,69 & 0,76 & 0 & 0,00 & 0,00 & 0,00 & 0,000000 & 0,00 & 0,000000 & 0,00 & $-0,001520$ \\
\hline Schinus terebinthifol & 0 & 0,00 & 0,00 & 0 & 0,00 & 0,00 & 0,00 & 0,000000 & 0,00 & 0,000000 & 0,00 & 0,000000 \\
\hline Senna bicapsularis & 0 & 0,00 & 0,00 & 0 & 0,00 & 0,00 & 0,00 & 0,000000 & 0,00 & 0,000000 & 0,00 & 0,000000 \\
\hline Baccharis serrulata & 1 & 1,31 & 0,12 & 0 & 0,00 & 0,00 & 100,00 & 0,000573 & 0,00 & 0,000000 & 0,00 & 0,000003 \\
\hline Peraobovata & 0 & 0,00 & 0,00 & 2 & 1,30 & 0,11 & 0,00 & 0,000000 & 0,00 & 0,000000 & 1,50 & 0,000770 \\
\hline
\end{tabular}

R. Árvore, Viçosa-MG, v.28, n.6, p.811-829, 2004 
Quadro 5 - cont.

Table 5 - cont.

\begin{tabular}{|c|c|c|c|c|c|c|c|c|c|c|c|c|}
\hline \multirow[t]{2}{*}{ ESPÉCIE } & \multicolumn{3}{|c|}{1997} & \multicolumn{3}{|c|}{2000} & \multirow{2}{*}{$\mathrm{TM}_{\mathrm{ij}}$} & \multirow[t]{2}{*}{$\mathrm{M}_{\mathrm{AB}}$} & \multirow{2}{*}{$\mathrm{TI}_{\mathrm{ij}}$} & \multirow[t]{2}{*}{$\mathrm{I}_{\mathrm{AB}}$} & \multirow[t]{2}{*}{ IPA } & \multirow[t]{2}{*}{$\mathrm{CB}$} \\
\hline & №I & IVI & $\overline{\mathrm{RNC}_{\mathrm{ij}}}$ & NoI & IVI & $\overline{\mathrm{RNC}_{\mathrm{ij}}}$ & & & & & & \\
\hline Prunus myrtifolia & 0 & 0,00 & 0,00 & 0 & 0,00 & 0,00 & 0,00 & 0,000000 & 0,00 & 0,000000 & 0,00 & 0,0000 \\
\hline Bysonima sp. & 0 & 0,00 & 0,00 & 0 & 0,00 & 0,00 & 0,00 & 0,000000 & 0,00 &, 000000 & 0,00 & 0,000000 \\
\hline Cabralea canjerana & 0 & 0,00 & 0,00 & 0 & 0,00 & 0,00 & 0,00 & 0,000000 & 0,00 &, 000000 & 0,00 & 0,000000 \\
\hline Erythroxylum deciduum & 2 & 2,36 & 0,24 & 0 & 0,00 & 0,00 & 0,00 & 0,000000 & 0,00 & 0,000000 & 0,00 & $-0,000570$ \\
\hline Xylosma pseudosalzmannii & 1 & 1,11 & 0,12 & 2 & 1,69 & 0,19 & 0,00 & 0,000000 & 50,00 & 0,000050 & 2,33 & 0,000209 \\
\hline Maytenus salicifolia & 1 & 1,13 & 0,12 & 1 & 0,85 & 0,09 & 0,00 & 0,000000 & 0,00 & 0,000000 & 0,00 & $-0,000038$ \\
\hline Rubus brasiliensis & 1 & 1,36 & 0,12 & 1 & 1,14 & 0,09 & 0,00 & 0,000000 & 0,00 & 0,000000 & 1,33 & 0,000247 \\
\hline Sapium glandulatun & 1 & 1,15 & 0,12 & 1 & 0,89 & 0,09 & 0,00 & 0,000000 & 0,00 & 0,000000 & 0,67 & 0,000067 \\
\hline Alomia fastigiata & 0 & 0,00 & 0,00 & 0 & 0,00 & 0,00 & 0,00 & 0,000000 & 0,00 & 0,000000 & 0,00 & 0,000000 \\
\hline Pipersp. & 0 & 0,00 & 0,00 & 0 & 0,00 & 0,00 & 0,00 & 0,000000 & 0,00 & 0,000000 & 0,00 & 0,000000 \\
\hline Tabebuia alba & 0 & 0,00 & 0,00 & 0 & 0,00 & 0,00 & 0,00 & 0,000000 & 0,00 & 0,000000 & 0,00 & 0,000000 \\
\hline Trichilia silvatica & 0 & 0,00 & 0,00 & 0 & 0,00 & 0,00 & 0,00 & 0,000000 & 0,00 & 0,000000 & 0,00 & 0,000000 \\
\hline Alibertia sessilis & 0 & 0,00 & 0,00 & 0 & 0,00 & 0,00 & 0,00 & 0,000000 & 0,00 & 0,000000 & 0,00 & 0,000000 \\
\hline Aniba firmula & 0 & 0,00 & 0,00 & 0 & 0,00 & 0,00 & 0,00 & 0,000000 & 0,00 & 0,000000 & 0,00 & 0,000000 \\
\hline Astronium graveo & 0 & 0,00 & 0,00 & 0 & 0,00 & 0,00 & 0,00 & 0,000000 & 0,00 & 0,000000 & 0,00 & 0,000000 \\
\hline Cedrela fissilis & 0 & 0,00 & 0,00 & 0 & 0,00 & 0,00 & 0,00 & 0,000000 & 0,00 & 0,000000 & 0,00 & 0,000000 \\
\hline Cryptocarya asche & 0 & 0,00 & 0,00 & 0 & 0,00 & 0,00 & 0,00 & 0,000000 & 0,00 & 0,000000 & 0,00 & 0,000000 \\
\hline Eupatorium sp. & 0 & 0,00 & 0,00 & 0 & 0,00 & 0,00 & 0,00 & 0,000000 & 0,00 & 0,000000 & 0,00 & 0,000000 \\
\hline Hovenia dulcis & 0 & 0,00 & 0,00 & 0 & 0,00 & 0,00 & 0,00 & 0,000000 & 0,00 & 0,000000 & 0,00 & 0,000000 \\
\hline Lamanonia ternata & 1 & 1,16 & 0,12 & 1 & 0,93 & 0,09 & 0,00 & 0,000000 & 0,00 & 0,000000 & 1,67 & 0,000190 \\
\hline Machaerium nyctitans & 0 & 0,00 & 0,00 & 0 & 0,00 & 0,00 & 0,00 & 0,000000 & 0,00 & 0,000000 & 0,00 & 0,000000 \\
\hline & 0 & 0,00 & 0,00 & 0 & 0,00 & 0,00 & 0,00 & 0,0 & 0,00 & 0,000 & 0,00 & 0,000000 \\
\hline Mataybajugl & 0 & 0,00 & 0,00 & 0 & 0,00 & 0,00 & 0,00 & 0,000000 & 0,00 & 0,000000 & 0,00 & 0,000000 \\
\hline Myrsine gardneriana & 0 & 0,00 & 0,00 & 0 & 0,00 & 0,00 & 0,00 & 0,000000 & 0,00 & 0,000000 & 0,00 & 0,000000 \\
\hline Myrsine lancifolia & 0 & 0,00 & 0,00 & 0 & 0,00 & 0,00 & 0,00 & 0,000000 & 0,00 & 0,000000 & 0,00 & 0,000000 \\
\hline Prokia crucis & 0 & 0,00 & 0,00 & 0 & 0,00 & 0,00 & 0,00 & 0,000000 & 0,00 & 0,000000 & 0,00 & 0,000000 \\
\hline Psidium cinereum & 1 & 1,21 & 0,12 & 1 & 0,93 & 0,09 & 0,00 & 0,000000 & 0,00 & 0,000000 & 0,33 & 0,000000 \\
\hline Rubiaceae 1 & 0 & 0,00 & 0,00 & 1 & 0,93 & 0,09 & 0,00 & 0,000000 & 100,00 & 0,000380 & 7,33 & 0,000380 \\
\hline Solanum gra & 0 & 0,00 & 0,00 & 0 & 0,0 & 0,00 & 0,00 & 0,000000 & 0,00 & 0,000000 & 0,00 & 0,000000 \\
\hline Solanum robustum & 0 & 0,00 & 0,00 & 0 & 0,00 & 0,00 & 0,00 & 0,000000 & 0,00 & 0,000000 & 0,00 & 0,000000 \\
\hline Solan & 0 & 0,00 & 0,00 & 0 & 0,00 & 0,00 & 0,00 & 0,000 & 0,00 & 0,000000 & 0,00 & 0,000000 \\
\hline Trembleya parviflora & 0 & 0,00 & 0,00 & 0 & 0,00 & 0,00 & 0,00 & 0,000000 & 0,00 & 0,000000 & 0,00 & 0,000000 \\
\hline
\end{tabular}

Quadro 6 - Dinâmica quantitativa dos parâmetros da classe 3 de altura da regeneração natural no Retiro-Branco, Poços de Caldas, MG. $\mathrm{N}^{\circ} \mathrm{I}=$ número de indivíduos, IVI = índice de valor de importância, $\mathrm{RNCij}=$ regeneração natural, $\mathrm{M}=$ mortalidade, $\mathrm{TM}=$ taxa de $\operatorname{mortalidade}(\%), \mathrm{I}=$ ingresso, $\mathrm{TI}=$ taxa de ingresso $(\%), \mathrm{IPA}=$ incremento periódico anual $(\mathrm{mm} / \mathrm{ano}), \mathrm{CB}=$ crescimento bruto $\left(\mathrm{m}^{2} / \mathrm{ha}\right)$ e $\mathrm{AB}=$ área basal

Table 6 - Quantitative dynamics of parameters for Class 3 of natural regeneration at Retiro-Branco, Poços de Caldas, Brazil. $N^{o} I=$ number of individuals, $I V I=$ importance value index, $R N C i j=$ natural regeneration, $M=$ mortality, $T M=$ mortality rate $(\%), I=$ ingrowth,$T I=$ ingrowth rates $(\%), I P A=$ annual increase $(\mathrm{mm} /$ year $), C B=$ growth $\left(m^{2} / h a\right)$, and $A B=$ basal area

\begin{tabular}{|c|c|c|c|c|c|c|c|c|c|c|c|c|}
\hline \multirow[t]{2}{*}{ ESPÉCIE } & \multicolumn{3}{|c|}{1997} & \multicolumn{3}{|c|}{2000} & \multirow[t]{2}{*}{$\mathrm{TM}_{\mathrm{ij}}$} & \multirow[t]{2}{*}{$\mathrm{M}_{\mathrm{AB}}$} & \multirow[t]{2}{*}{$\mathrm{TI}_{\mathrm{ij}}$} & \multirow[t]{2}{*}{$\mathrm{I}_{\mathrm{AB}}$} & \multirow[t]{2}{*}{ IPA } & \multirow[t]{2}{*}{$\mathrm{CB}$} \\
\hline & NoI & IVI & $\mathrm{RNC}_{\mathrm{ij}}$ & NoI & IVI & $\mathrm{RNC}_{\mathrm{ij}}$ & & & & & & \\
\hline Miconia sellowiana & 54 & 90,10 & 2,73 & 167 & 103,32 & 4,10 & 3,70 & 0,010739 & 1,20 & 0,000604 & 8,96 & 0,491866 \\
\hline Psychotria sessilis & 23 & 43,57 & 1,36 & 42 & 28,68 & 1,41 & 13,04 & 0,006602 & 4,76 & 0,004513 & 5,09 & 0,071250 \\
\hline Leandra melastomoides & 2 & 5,22 & 0,24 & 9 & 8,65 & 0,61 & 50,00 & 0,000908 & 0,00 & 0,009637 & 4,22 & 0,012422 \\
\hline Clethra scabra & 26 & 45,44 & 1,82 & 59 & 40,20 & 2,08 & 3,85 & 0,002290 & 0,00 & 0,078361 & 6,38 & 0,130227 \\
\hline
\end{tabular}

- - - - - - - - - - - - - - - - - - - - - - - - - -

Continued... 
Quadro 6 - cont.

Table 6 - cont.

\begin{tabular}{|c|c|c|c|c|c|c|c|c|c|c|c|c|}
\hline \multirow[t]{2}{*}{ ESPÉCIE } & \multicolumn{3}{|c|}{1997} & \multicolumn{3}{|c|}{2000} & \multirow[t]{2}{*}{$\mathrm{TM}_{\mathrm{ij}}$} & \multirow[t]{2}{*}{$\mathrm{M}_{\mathrm{AB}}$} & \multirow[t]{2}{*}{$\mathrm{TI}_{\mathrm{ij}}$} & \multirow[t]{2}{*}{$\mathrm{I}_{\mathrm{AB}}$} & \multirow[t]{2}{*}{ IPA } & \multirow[t]{2}{*}{$\mathrm{CB}$} \\
\hline & №I & IVI & $\overline{\mathrm{RNC}_{\mathrm{ij}}}$ & NoI & IVI & $\mathrm{RNC}_{\mathrm{ij}}$ & & & & & & \\
\hline Baccharis semiserrata & 1 & 2,24 & 0,12 & 1 & 1,15 & 0,09 & 100,00 & 0,000531 & 0,00 & 0,000346 & 1,33 & $-0,000077$ \\
\hline Myrsine umbellata & 20 & 36,98 & 1,38 & 36 & 27,42 & 1,45 & 5,00 & 0,001134 & 2,78 & 0,000661 & 6,13 & 0,071995 \\
\hline Miconia pepericarpa & 0 & 0,00 & 0,00 & 3 & 3,66 & 0,28 & 0,00 & 0,000000 & 0,00 & 0,003938 & 6,56 & 0,003943 \\
\hline Leandra lacunosa & 0 & 0,00 & 0,00 & 0 & 0,00 & 0,00 & 0,00 & 0,000000 & 0,00 & 0,000000 & 0,00 & 0,000000 \\
\hline Baccharis dracunculifolia & 9 & 18,21 & 0,71 & 10 & 13,45 & 0,85 & 33,33 & 0,003581 & 0,00 & 0,013281 & 8,70 & 0,024785 \\
\hline Tibouchina candolleana & 0 & 0,00 & 0,00 & 6 & 5,62 & 0,41 & 0,00 & 0,000000 & 0,00 & 0,008108 & 4,78 & 0,008113 \\
\hline Mimosa scabrella & 0 & 0,00 & 0,00 & 6 & 6,12 & 0,41 & 0,00 & 0,000000 & 0,00 & 0,007550 & 11,17 & 0,015096 \\
\hline Ocotea pulchella & 0 & 0,00 & 0,00 & 2 & 2,34 & 0,19 & 0,00 & 0,000000 & 0,00 & 0,001235 & 1,67 & 0,001235 \\
\hline Casearia sylvestris & 1 & 2,29 & 0,12 & 2 & 2,49 & 0,19 & 0,00 & 0,000000 & 0,00 & 0,002642 & 3,00 & 0,002404 \\
\hline Blepharocalyx salicifolius & 0 & 0,00 & 0,00 & 0 & 0,00 & 0,00 & 0,00 & 0,000000 & 0,00 & 0,000000 & 0,00 & 0,000000 \\
\hline Alchornea triplinervia & 1 & 2,64 & 0,12 & 2 & 2,98 & 0,19 & 0,00 & 0,000000 & 0,00 & 0,003632 & 14,00 & 0,008094 \\
\hline Cordia superba & 2 & 5,21 & 0,24 & 4 & 5,23 & 0,37 & 0,00 & 0,000000 & 0,00 & 0,004892 & 4,58 & 0,006185 \\
\hline Myrcia rostrata & 0 & 0,00 & 0,00 & 0 & 0,00 & 0,00 & 0,00 & 0,000000 & 0,00 & 0,000000 & 0,00 & 0,000000 \\
\hline Cestrum amictum & 3 & 11,79 & 0,37 & 4 & 7,74 & 0,37 & 0,00 & 0,000000 & 0,00 & 0,001257 & 12,00 & 0,021841 \\
\hline Aureliana velutina & 0 & 0,00 & 0,00 & 0 & 0,00 & 0,00 & 0,00 & 0,000000 & 0,00 & 0,000000 & 0,00 & 0,000000 \\
\hline Siphoneugena densiflora & 0 & 0,00 & 0,00 & 0 & 0,00 & 0,00 & 0,00 & 0,000000 & 0,00 & 0,000000 & 0,00 & 0,000000 \\
\hline Vernonia westiniana & 0 & 0,00 & 0,00 & 1 & 1,18 & 0,09 & 0,00 & 0,000000 & 0,00 & 0,000707 & 7,67 & 0,000703 \\
\hline Cupania vernalis & 0 & 0,00 & 0,00 & 0 & 0,00 & 0,00 & 0,00 & 0,000000 & 0,00 & 0,000000 & 0,00 & 0,000000 \\
\hline Myrciaformosiana & 0 & 0,00 & 0,00 & 0 & 0,00 & 0,00 & 0,00 & 0,000000 & 0,00 & 0,000000 & 0,00 & 0,000000 \\
\hline Vernonia ferruginea & 6 & 18,40 & 0,63 & 8 & 13,93 & 0,67 & 0,00 & 0,000000 & 0,00 & 0,007736 & 13,50 & 0,049353 \\
\hline Eupatorium inulaefolium & 0 & 0,00 & 0,00 & 2 & 2,66 & 0,19 & 0,00 & 0,000000 & 0,00 & 0,005655 & 13,67 & 0,005653 \\
\hline Baccharis punctulata & 0 & 0,00 & 0,00 & 0 & 0,00 & 0,00 & 0,00 & 0,000000 & 0,00 & 0,000000 & 0,00 & 0,000000 \\
\hline Pimentapseudocaryophyllus & 0 & 0,00 & 0,00 & 0 & 0,00 & 0,00 & 0,00 & 0,000000 & 0,00 & 0,000000 & 0,00 & 0,000000 \\
\hline Cordia ecalyculata & 0 & 0,00 & 0,00 & 0 & 0,00 & 0,00 & 0,00 & 0,000000 & 0,00 & 0,000000 & 0,00 & 0,000000 \\
\hline Casearia decandra & 0 & 0,00 & 0,00 & 2 & 2,37 & 0,19 & 0,00 & 0,000000 & 0,00 & 0,001665 & 5,17 & 0,001663 \\
\hline Schefflera angustissima & 0 & 0,00 & 0,00 & 1 & 1,18 & 0,09 & 0,00 & 0,000000 & 0,00 & 0,000707 & 4,33 & 0,000703 \\
\hline Myrciaria tenella & 0 & 0,00 & 0,00 & 0 & 0,00 & 0,00 & 0,00 & 0,000000 & 0,00 & 0,000000 & 0,00 & 0,000000 \\
\hline Vernonia polyanthes & 0 & 0,00 & 0,00 & 2 & 3,69 & 0,19 & 0,00 & 0,000000 & 0,00 & 0,019878 & 12,17 & 0,019874 \\
\hline Gomidesia anacardiaefolia & 0 & 0,00 & 0,00 & 1 & 1,18 & 0,09 & 0,00 & 0,000000 & 0,00 & 0,000755 & 5,00 & 0,000751 \\
\hline Myrcia tomentosa & 0 & 0,00 & 0,00 & 0 & 0,00 & 0,00 & 0,00 & 0,000000 & 0,00 & 0,000000 & 0,00 & 0,000000 \\
\hline Roupala brasiliensis & 0 & 0,00 & 0,00 & 0 & 0,00 & 0,00 & 0,00 & 0,000000 & 0,00 & 0,000000 & 0,00 & 0,000000 \\
\hline Alibertia concolor & 0 & 0,00 & 0,00 & 0 & 0,00 & 0,00 & 0,00 & 0,000000 & 0,00 & 0,000000 & 0,00 & 0,000000 \\
\hline Cybianthus cuneifolius & 0 & 0,00 & 0,00 & 0 & 0,00 & 0,00 & 0,00 & 0,000000 & 0,00 & 0,000000 & 0,00 & 0,000000 \\
\hline Daphnopsis fasciculata & 0 & 0,00 & 0,00 & 0 & 0,00 & 0,00 & 0,00 & 0,000000 & 0,00 & 0,000000 & 0,00 & 0,000000 \\
\hline Vochysia tucanorum & 2 & 7,87 & 0,24 & 3 & 5,39 & 0,28 & 0,00 & 0,000000 & 0,00 & 0,003019 & 8,78 & 0,012483 \\
\hline Zanthoxylum rhoifolium & 0 & 0,00 & 0,00 & 1 & 1,18 & 0,09 & 0,00 & 0,000000 & 0,00 & 0,000804 & 2,00 & 0,000808 \\
\hline Miconia albicans & 0 & 0,00 & 0,00 & 3 & 2,77 & 0,20 & 0,00 & 0,000000 & 0,00 & 0,003578 & 4,22 & 0,003582 \\
\hline Schinus terebinthifolius & 0 & 0,00 & 0,00 & 0 & 0,00 & 0,00 & 0,00 & 0,000000 & 0,00 & 0,000000 & 0,00 & 0,000000 \\
\hline Senna bicapsularis & 0 & 0,00 & 0,00 & 0 & 0,00 & 0,00 & 0,00 & 0,000000 & 0,00 & 0,000000 & 0,00 & 0,000000 \\
\hline Baccharis serrulata & 0 & 0,00 & 0,00 & 0 & 0,00 & 0,00 & 0,00 & 0,000000 & 0,00 & 0,000000 & 0,00 & 0,000000 \\
\hline Peraobovata & 0 & 0,00 & 0,00 & 0 & 0,00 & 0,00 & 0,00 & 0,000000 & 0,00 & 0,000000 & 0,00 & 0,000000 \\
\hline
\end{tabular}

R. Árvore, Viçosa-MG, v.28, n.6, p.811-829, 2004 
Quadro 6 cont.

Table 6 cont.

\begin{tabular}{|c|c|c|c|c|c|c|c|c|c|c|c|c|}
\hline \multirow[t]{2}{*}{ ESPÉCIE } & \multicolumn{3}{|c|}{1997} & \multicolumn{3}{|c|}{2000} & \multirow[t]{2}{*}{$\mathrm{TM}_{\mathrm{ij}}$} & \multirow[t]{2}{*}{$\mathrm{M}_{\mathrm{AB}}$} & \multirow[t]{2}{*}{$\mathrm{TI}_{\mathrm{ij}}$} & \multirow[t]{2}{*}{$\mathrm{I}_{\mathrm{AB}}$} & \multirow[t]{2}{*}{ IPA } & \multirow[t]{2}{*}{$\mathrm{CB}$} \\
\hline & NoI & IVI & $\overline{\mathrm{RNC}_{\mathrm{ij}}}$ & NoI & IVI & $\overline{\mathrm{RNC}_{\mathrm{ij}}}$ & & & & & & \\
\hline Prunus myrtifolia & 0 & 0,00 & 0,00 & 0 & 0,00 & 0,00 & 0,00 & 0,000000 & 0,00 & 0,000000 & 0,00 & 0,000000 \\
\hline Byrsonima sp. & 0 & 0,00 & 0,00 & 0 & 0,00 & 0,00 & 0,00 & 0,000000 & 0,00 & 0,000000 & 0,00 & 0,000000 \\
\hline Cabralea canjerana & 0 & 0,00 & 0,00 & 0 & 0,00 & 0,00 & 0,00 & 0,000000 & 0,00 & 0,000000 & 0,00 & 0,000000 \\
\hline Erythroxylum deciduum & 0 & 0,00 & 0,00 & 0 & 0,00 & 0,00 & 0,00 & 0,000000 & 0,00 & 0,000000 & 0,00 & 0,000000 \\
\hline Xylosma pseudosalzmannii & 0 & 0,00 & 0,00 & 0 & 0,00 & 0,00 & 0,00 & 0,000000 & 0,00 & 0,000000 & 0,00 & 0,000000 \\
\hline Maytenus salicifolia & 0 & 0,00 & 0,00 & 0 & 0,00 & 0,00 & 0,00 & 0,000000 & 0,00 & 0,000000 & 0,00 & 0,000000 \\
\hline Rubus brasiliensis & 0 & 0,00 & 0,00 & 0 & 0,00 & 0,00 & 0,00 & 0,000000 & 0,00 & 0,000000 & 0,00 & 0,000000 \\
\hline Sapium glandulatum & 0 & 0,00 & 0,00 & 0 & 0,00 & 0,00 & 0,00 & 0,000000 & 0,00 & 0,000000 & 0,00 & 0,000000 \\
\hline Alomia fastigiata & 0 & 0,00 & 0,00 & 0 & 0,00 & 0,00 & 0,00 & 0,000000 & 0,00 & 0,000000 & 0,00 & 0,000000 \\
\hline Piper sp. & 0 & 0,00 & 0,00 & 0 & 0,00 & 0,00 & 0,00 & 0,000000 & 0,00 & 0,000000 & 0,00 & 0,000000 \\
\hline Tabebuia alba & 0 & 0,00 & 0,00 & 0 & 0,00 & 0,00 & 0,00 & 0,000000 & 0,00 & 0,000000 & 0,00 & 0,000000 \\
\hline Trichilia silvatica & 0 & 0,00 & 0,00 & 0 & 0,00 & 0,00 & 0,00 & 0,000000 & 0,00 & 0,000000 & 0,00 & 0,000000 \\
\hline Alibertia sessilis & 0 & 0,00 & 0,00 & 0 & 0,00 & 0,00 & 0,00 & 0,000000 & 0,00 & 0,000000 & 0,00 & 0,000000 \\
\hline Aniba firmula & 1 & 2,78 & 0,12 & 1 & 1,40 & 0,09 & 0,00 & 0,000000 & 0,00 & 0,000000 & 3,33 & 0,000998 \\
\hline Astronium graveolens & 0 & 0,00 & 0,00 & 0 & 0,00 & 0,00 & 0,00 & 0,000000 & 0,00 & 0,000000 & 0,00 & 0,000000 \\
\hline Cedrela fissilis & 0 & 0,00 & 0,00 & 0 & 0,00 & 0,00 & 0,00 & 0,000000 & 0,00 & 0,000000 & 0,00 & 0,000000 \\
\hline Cryptocarya aschersoniana & 0 & 0,00 & 0,00 & 0 & 0,00 & 0,00 & 0,00 & 0,000000 & 0,00 & 0,000000 & 0,00 & 0,000000 \\
\hline Eupatorium sp. & 0 & 0,00 & 0,00 & 0 & 0,00 & 0,00 & 0,00 & 0,000000 & 0,00 & 0,000000 & 0,00 & 0,000000 \\
\hline Hovenia dulcis & 0 & 0,00 & 0,00 & 0 & 0,00 & 0,00 & 0,00 & 0,000000 & 0,00 & 0,000000 & 0,00 & 0,000000 \\
\hline Lamanonia ternata & 0 & 0,00 & 0,00 & 0 & 0,00 & 0,00 & 0,00 & 0,000000 & 0,00 & 0,000000 & 0,00 & 0,000000 \\
\hline Machaerium nyctitans & 0 & 0,00 & 0,00 & 0 & 0,00 & 0,00 & 0,00 & 0,000000 & 0,00 & 0,000000 & 0,00 & 0,000000 \\
\hline Machaerium stipitatum & 0 & 0,00 & 0,00 & 0 & 0,00 & 0,00 & 0,00 & 0,000000 & 0,00 & 0,000000 & 0,00 & 0,000000 \\
\hline Matayba juglandifolia & 0 & 0,00 & 0,00 & 0 & 0,00 & 0,00 & 0,00 & 0,000000 & 0,00 & 0,000000 & 0,00 & 0,000000 \\
\hline Myrsine gardneriana & 0 & 0,00 & 0,00 & 0 & 0,00 & 0,00 & 0,00 & 0,000000 & 0,00 & 0,000000 & 0,00 & 0,000000 \\
\hline Myrsine lancifolia & 0 & 0,00 & 0,00 & 0 & 0,00 & 0,00 & 0,00 & 0,000000 & 0,00 & 0,000000 & 0,00 & 0,000000 \\
\hline Prokia crucis & 0 & 0,00 & 0,00 & 0 & 0,00 & 0,00 & 0,00 & 0,000000 & 0,00 & 0,000000 & 0,00 & 0,000000 \\
\hline Psidium cinereum & 0 & 0,00 & 0,00 & 0 & 0,00 & 0,00 & 0,00 & 0,000000 & 0,00 & 0,000000 & 0,00 & 0,000000 \\
\hline Rubiaceae 1 & 0 & 0,00 & 0,00 & 0 & 0,00 & 0,00 & 0,00 & 0,000000 & 0,00 & 0,000000 & 0,00 & 0,000000 \\
\hline Solanum granuloso-leprosum & 1 & 3,82 & 0,12 & 1 & 2,41 & 0,09 & 0,00 & 0,000000 & 0,00 & 0,000000 & 18,00 & 0,010070 \\
\hline Solanum robustum & 0 & 0,00 & 0,00 & 0 & 0,00 & 0,00 & 0,00 & 0,000000 & 0,00 & 0,000000 & 0,00 & 0,000000 \\
\hline Solanum swartzianum & 0 & 0,00 & 0,00 & 0 & 0,00 & 0,00 & 0,00 & 0,000000 & 0,00 & 0,000000 & 0,00 & 0,000000 \\
\hline Trembleya parviflora & 1 & 3,39 & 0,12 & 1 & 1,59 & 0,09 & 0,00 & 0,000000 & 0,00 & 0,000000 & 2,33 & 0,000665 \\
\hline
\end{tabular}

A dinâmica dos grupos de espécies, observada entre 1997 e 2000, indica que, no primeiro inventário, as espécies secundárias exerciam uma supremacia em número de indivíduos, em relação às pioneiras e clímax, que por sua vez apresentaram relação de paridade de número de indivíduos entre si. No segundo inventário ocorreu uma relação de paridade do número de indivíduos entre os grupos ecológicos e de pioneiras, secundárias e clímax, estabelecida pelos respectivos comportamentos dos grupos quanto à mortalidade e ao ingresso. As espécies secundárias apresentaram menor ingresso e maior mortalidade na classe 1 de altura em relação aos dois outros grupos. As secundárias foram as que exibiram maior crescimento total e maiores taxas de movimentação entre as classes de altura. No Quadro 7 é apresentado o resumo dos parâmetros, da mortalidade, do ingresso e da emigração (indivíduos que passaram para as classes de altura subseqüentes), por grupo ecológico e por classe de tamanho.

R. Árvore, Viçosa-MG, v.28, n.6, p.811-829, 2004 
Quadro 7 - Parâmetros de mortalidade, ingresso, emigração e crescimento, por grupo ecológico e por classe de diâmetro, no Retiro-Branco, em Poços de Caldas, MG, entre 1997 e 2000. GE = grupo ecológico, № I = número de indivíduos, $\mathrm{RN}=$ regeneração natural, $\mathrm{P}=$ pioneiras, $\mathrm{S}=$ secundárias, e $\mathrm{C}=$ clímax

Table 7 - Outgrowth, ingrowth, emigration and growth, for ecological group and for diameter class, at Retiro-Branco, Poços de Caldas, Brazil, 1997 and 2000. GE = ecological group, $N^{o} I=$ number of individuals, RN = natural regeneration, $P=$ pioneers, $S=$ secondary, and $C=$ climax

\begin{tabular}{|c|c|c|c|c|c|c|c|c|c|}
\hline \multirow[t]{2}{*}{ Parâmetro } & \multirow{2}{*}{$\begin{array}{c}\mathrm{GE} \\
\mathrm{P}\end{array}$} & \multicolumn{2}{|c|}{ Classe1 } & \multicolumn{2}{|c|}{ Classe 2} & \multicolumn{2}{|c|}{ Classe 3} & \multicolumn{2}{|c|}{ RN Total } \\
\hline & & 169 & $(8,68 \%)$ & 13 & $(0,67 \%)$ & 5 & $(0,26 \%)$ & 187 & $(9,61 \%)$ \\
\hline Mortalidade & $\mathrm{S}$ & 265 & $(13,62 \%)$ & 32 & $(1,64 \%)$ & 3 & $(0,15 \%)$ & 300 & $(15,42 \%)$ \\
\hline (№I) & $\mathrm{C}$ & 128 & $(6,58 \%)$ & 13 & $(0,67 \%)$ & 4 & $(0,21 \%)$ & 145 & $(7,45 \%)$ \\
\hline Total & & 562 & $(28,88 \%)$ & 58 & $(2,90 \%)$ & 12 & $(0,62 \%)$ & 632 & $(32,487 \%)$ \\
\hline & $P$ & 559 & $(28,73 \%)$ & 21 & $(1,08 \%)$ & 0 & $(0,00 \%)$ & 580 & $(29,80 \%)$ \\
\hline Ingresso & $\mathrm{S}$ & 392 & $(20,14 \%)$ & 30 & $(1,54 \%)$ & 2 & $(0,10 \%)$ & 424 & $(21,79 \%)$ \\
\hline (№ I) & $\mathrm{C}$ & 536 & $(27,54 \%)$ & 21 & $(1,08 \%)$ & 3 & $(0,15 \%)$ & 560 & $(28,78 \%)$ \\
\hline Total & & 1.487 & $(76,41 \%)$ & 72 & $(3,70 \%)$ & 5 & $(0,26 \%)$ & 1.564 & $(80,37 \%)$ \\
\hline & $P$ & & 50 & $(2,57 \%)$ & 130 & $(6,68 \%)$ \\
\hline $\begin{array}{l}\text { Emigração } \\
\text { (№ I) }\end{array}$ & $\mathrm{S}$ & \multicolumn{4}{|c|}{$\begin{array}{c}80(4,11 \%) \\
134(6,89 \%)\end{array}$} & 94 & $(4,83 \%)$ & 228 & $(11,72 \%)$ \\
\hline & $\mathrm{C}$ & \multirow{2}{*}{\multicolumn{4}{|c|}{$\begin{array}{c}68(3,49 \%) \\
282(14,49 \%)\end{array}$}} & 38 & $(1,95 \%)$ & 106 & $(5,45 \%)$ \\
\hline Total & & & & & & 182 & $(9,35 \%)$ & 464 & $(23,84 \%)$ \\
\hline & $\mathrm{P}$ & 0,12 & $(1,55 \%)$ & $-0,06$ & $(-0,79 \%)$ & 3,15 & $(39,92 \%)$ & 3,21 & $(40,72 \%)$ \\
\hline Crescimento & $\mathrm{S}$ & 0,06 & $(0,79 \%)$ & 0,05 & $(0,66 \%)$ & 5,36 & $(67,89 \%)$ & 5,47 & $(68,73 \%)$ \\
\hline (m2/ha) & $\mathrm{C}$ & 0,20 & $(2,55 \%)$ & 0,26 & $(3,35 \%)$ & 1,51 & $(19,19 \%)$ & 1,97 & $(25,09 \%)$ \\
\hline Total & & 0,38 & $(4,90 \%)$ & 0,25 & $(3,21 \%)$ & 10,01 & $(127,00 \%)$ & 10,65 & $(135,02 \%)$ \\
\hline
\end{tabular}

No inventário florestal de 1997, das 63 espécies encontradas, 27 apresentavam indivíduos apenas na classe 1 (entre 0,30 e 1,50 m) de altura da regeneração natural. Sobre essas espécies, pode-se supor que: são espécies que chegaram e, a partir desse momento, passaram a ter condições favoráveis para o seu desenvolvimento, ou são espécies que chegaram, mas não conseguiram ter condições favoráveis para se desenvolver e ocupar as classes de altura do povoamento. No inventário florestal de 2000, das 27 espécies, 16 mantiveram-se apenas com indivíduos na classe $1 \mathrm{de}$ altura, sendo oito clímax (Cryptocarya aschersoniana, Cupania vernalis, Cybianthus cuneifolius, Myrsine lancifolia, Hovenia dulcis, Machaerium nyctitans, Machaerium stipitatum, Matayba juglandifolia), cinco secundárias (Cabralea canjerana, Cedrella fissilis, Myrcia formosiana, Myrciaria tenella, Prunus myrtifolia) e três pioneiras (Alomia fastigiata, Eupatorium sp., Senna bicapsularis), reforçando os indícios de que essas são espécies que chegam, mas não conseguem ter condições favoráveis para se desenvolver ao longo das classes de altura do povoamento; nove espécies, sendo quatro secundárias (Leandra lacunosa, Pera obovata, Pimenta pseudocaryophyllus e Roupala brasiliensis), três clímax (Myrcia tomentosa,
Siphoneugena densiflora e Daphnopsis fasciculata) e duas pioneiras (Baccharis punctulata e Schefflera angustissima), conseguiram estar presentes em pelo menos duas das classes de altura (classes 1 e 2 ou classes 1 e 3), reforçando os indícios de que essas são espécies que chegaram e estão tendo condições favoráveis para o seu desenvolvimento, e duas espécies, sendo uma pioneira (Eupatorium inulaefolium) e uma secundária (Gomidesia anacardiaefolia), passando a ter indivíduos nas três classes de altura, indicando também que são espécies que chegaram e estão tendo condições favoráveis para o seu desenvolvimento, refletindo, de forma mais clara, pelo seu melhor desempenho na ocupação dos estratos de altura.

As três espécies que no inventário de 1997 apresentaram indivíduos somente na classe 3 de altura (maior que $3 \mathrm{~m}$ ) mantiveram o mesmo comportamento no inventário de 2000. Das três espécies, foram duas pioneiras (Solanum granulosum-leprosum e Trembleya parviflora) e uma secundária (Aniba firmula). Sobre essas espécies permanecem os indícios de sua baixa eficiência na recolonização do Retiro-Branco.

No inventário realizado em 2000, das 14 espécies novas que surgiram, 13 apresentaram indivíduos apenas 
na classe 1 de altura (entre 0,30 e 1,50 m), sendo: oito secundárias (Alibertia sessilis, Astronium graveolens, Byrsonima sp., Cordia ecalyculata, Prokia crucis, Rubiaceae 1, Tabebuia alba e Trichilia silvatica), quatro pioneiras (Piper sp., Schinus terebinthifolius, Solanum robustum e Solanum swartzianum) e uma clímax (Myrsine gardneriana). Uma espécie nova, a pioneira Aureliana velutina, apresentou indivíduos nas classes 1 e 2 de altura (entre $0,30 \mathrm{~m}$ e 3,00 m). Em relação ao parâmetro regeneração natural total, as 10 espécies de melhor desempenho em 1997 também foram as de melhor desempenho em 2000. A espécie Mimosa scabrella passou a ter indivíduos nas três classes de altura da regeneração (Figura 1).

O processo de regeneração natural no Retiro-Branco foi iniciado sob um povoamento puro de Mimosa scabrella, implantado como componente arbóreo do processo de reabilitação, o que muito provavelmente favoreceu o estabelecimento e desenvolvimento de espécies secundárias e clímax nos primeiros estados de estruturação da regeneração natural, conforme observado no inventário de 1997.

Nappo et al. (2000a) relataram o declínio do povoamento puro de Mimosa scabrella implantado no local de estudo em função do grande número de indivíduos mortos. Esses relatos corroboram os estudos agora realizados na mesma área, sendo importantes para o entendimento da dinâmica dos parâmetros das espécies quanto aos grupos ecológicos, onde foram observados o menor ingresso de espécies secundárias e ao mesmo tempo o domínio desse grupo nas classes maiores de altura, bem como o maior ingresso de espécies pioneiras, provavelmente associado às clareiras formadas. O comportamento das espécies clímax parece estar associado aos microambientes proporcionados pelo aumento de dominância das espécies secundárias nas classes de altura superiores.

O processo de sucessão na área do Retiro-Branco pode ser entendido conforme a teoria de sucessão de Connell e Slatyer (1977) quanto à "facilitação", em que o povoamento puro de Mimosa scabrella, num primeiro momento do processo de reabilitação, cumpriu seu papel de agente facilitador do processo, tendo formado condições de dossel que favoreceram as espécies secundárias. Num segundo momento, com o declínio do povoamento e a consequiente abertura de dossel, a facilitação desenvolveu-se favoravelmente para a ocupação do sítio por espécies pioneiras.

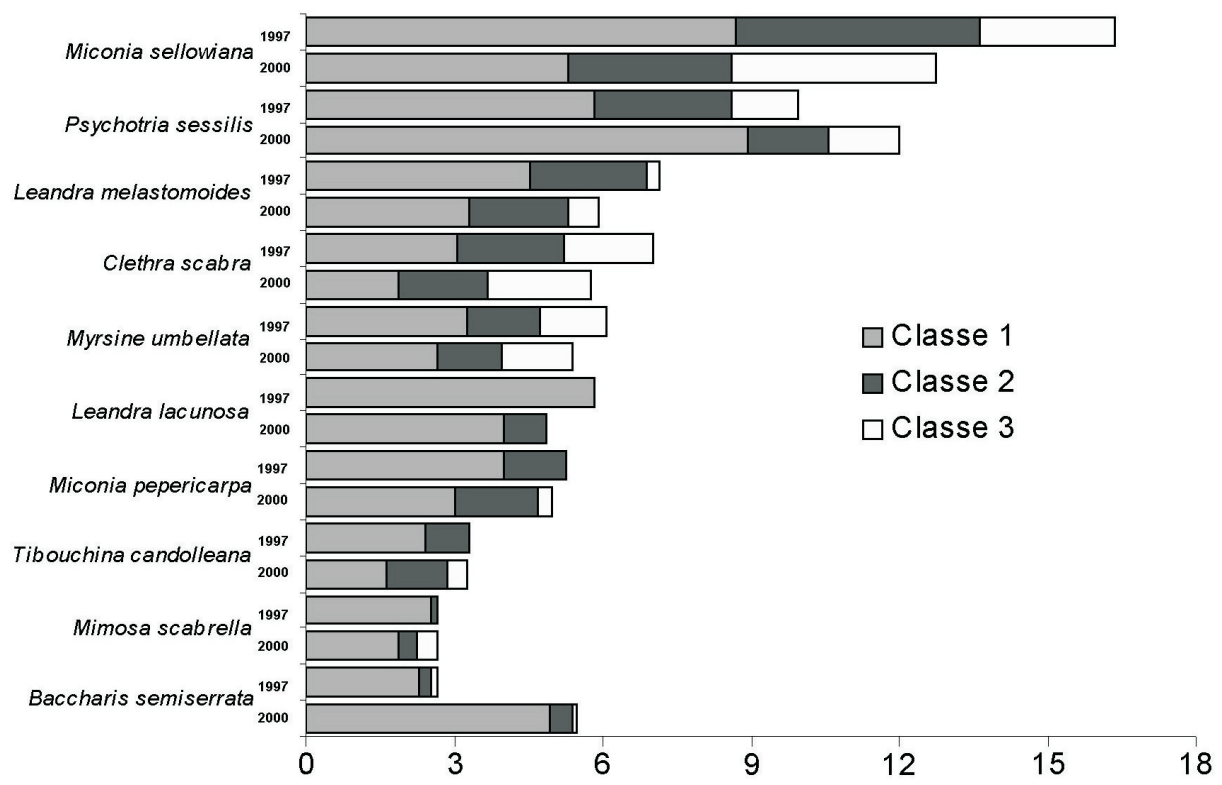

Figura 1 - Distribuição dos valores de regeneração natural das 10 espécies de maior importância nos inventários de 1997 e 2000, no Retiro-Branco, em Poços de Caldas, MG.

Figure 1 - Distribution of values for natural regeneration of the 10 most important species in 1997 and 2000 inventories for Retiro-Branco, Poços de Caldas, Brazil. 


\section{CONCLUSÕES}

A regeneração natural no Retiro-Branco, em Poços de Caldas, MG, passa por um processo de estratificação, no qual as espécies pioneiras e clímax são as principais componentes do estrato inferior e as secundárias, as principais componentes do estrato superior.

O povoamento florestal do Retiro-Branco está sobre intensa atividade de estruturação, caracterizando o estágio inicial do processo de sucessão.

As espécies secundárias são as de maior dominância nas maiores classes de altura e de diâmetro. São as principais responsáveis pela edificação do estrato superior, em especial a espécie Miconia sellowiana.

As espécies Miconia sellowiana, Psychotria sessilis, Leandra melastomoides, Clethra scabra, Myrsine umbellata, Miconia pepericarpa, Tibouchina candolleana, Cordia superba, Cestrum amictum, Alchornea triplinervia, Casearia sylvestris, Blepharocalyx salicifolius, Myrcia rostrata e Schinus terebinthifolius reafirmam o desempenho superior na colonização e estruturação da área de estudo, sendo indicadas como espécies para uso nos programas de reabilitação de áreas mineradas em condições semelhantes sobre a estratégia sucessional, ou seja, com a determinação de proporção e número de espécies pioneiras, secundárias e clímax, com o arranjo de distribuição das espécies e com o momento de plantio dessas espécies (simultâneo ou escalonado).

\section{REFERÊNCIAS BIBLIOGRÁFICAS}

AZEVEDO, C. P.; SOUZA, A. L.; JESUS, R. M. Um modelo de matriz de transição para prognose do crescimento de um povoamento natural remanescente não manejado de mata atlântica. Revista Árvore, v. 19, n. 2, p. 187-199, 1995.

CARVAlho, J. O. P. Subsídios para o manejo de florestas naturais na Amazônia Brasileira: Resultados de pesquisa da EMBRAPA/IBDF - PNF. Belém-PA: EMBRAPA/CAPTU, 1987. 35 p. (EMBRAPA/ CAPTU - Documentos, 43).

CONNELL, J. H.; SLATYER, R. Mechanisms of succession in natural communities and their role in community stability and organization. The American Naturalist, v. 111, p. 1119-1144, 1977.

R. Árvore, Viçosa-MG, v.28, n.6, p.811-829, 2004
CURTIS, J. T.; McINTOSH, R. P. An upland forest continuum in the prarie-forest border region of Wisconsin. Ecology, v. 32, p. 476-496, 1951.

FERREIRA, R. L. C. Estrutura e dinâmica de uma floresta secundária de transição, Rio Vermelho e Serra Azul de Minas, MG. 1997. 208f. Tese (Doutorado em Ciência Florestal) - Universidade Federal de Viçosa, Viçosa, 1997.

HOSOKAWA, R. T. Manejo e economia de florestas. Roma: FAO, 1986. 125 p.

HUSCH, B.; MILLER, C. I.; BEERS, T. W. Forest mensuration. Malabar: Krieger, 1993. 402p.

LAMPRECHT, H. Ensayo sobre la estructura florística de la parte sur-oriental del bosque universitario «El Caimital», Estado Barinas. Revista Forestal Venezolana, v. 7, n. 10/ 11 , p. 77-119, 1964.

MAGURRAN, A. E. Ecological diversity and its measurement. New Jersey: Princeton University, 1988. 179 p.

MARTINS, F. R. Estrutura de uma floresta mesófila. Campinas: UNICAMP, 1993. $246 \mathrm{p}$.

NAPPO, M. E.; FONTES, M. A. L.; OLIVEIRAFILHO, A. T. Suficiência amostral e análise do tamanho de parcelas para o estudo da regeneração natural do sub-bosque de povoamentos homogêneos de Mimosa scabrella Bentham, em área minerada, em Poços de Caldas, MG. Revista Árvore, v. 23, n. 4, p. 443-453, 1999.

NAPPO, M. E., FONTES, M. A. L., OLIVEIRAFILHO, A. T. Regeneração natural em sub-bosque de povoamentos homogêneos de Mimosa scabrella Bentham, implantados em áreas mineradas, em Poços de Caldas, Minas Gerais. Revista Árvore, v. 24, n. 3, p. 297-307, 2000a.

NAPPO, M. E., OLIVEIRA-FILHO, A. T., MARTINS, S. V. A estrutura do sub-bosque de povoamentos homogêneos de Mimosa scabrella Bentham, em área minerada, em Poços de Caldas, MG. Ciência Florestal, v. 10, n. 2, p. 17-29, 2000b.

POOLE, R. W. An introduction to quantitative ecology. New York: McGrawHill, 1974. 532p. 
REZENDE, M. L. Regeneração natural de espécies florestais em sub-bosque de um povoamento de Eucalyptus grandis e de mata secundária, no município de Viçosa, Zona da Mata-MG. 1995. 116 f. Dissertação (Mestrado em Ciência Florestal) Universidade Federal de Viçosa, Viçosa, 1995.

VIDAL, E.; VIANA, V.; BATISTA, J. L. F. Efeitos da exploração predatória e planejada sobre a diversidade de espécies na Amazônia Oriental. Revista Árvore, v. 22, n. 4, p.503-520, 1998.
VOLPATO, M. M. L. Regeneração natural de uma floresta secundária no domínio de mata atlântica: uma análise fitossociológica. 1994. $123 \mathrm{f}$. Dissertação (Mestrado em Ciência Florestal) Universidade Federal de Viçosa, Viçosa. 1994.

WERNECK, M. S., FRANCESCHINELLI, E. V., TAMEIRÃO-NETO, E. Mudanças na florística e estrutura de uma floresta decídua durante um período de quatro anos (1994-1998), na região do Triângulo Mineiro, MG. Revista Brasileira de Botânica, v. 23, n. 4, p. 399-411, 2000. 